NBER WORKING PAPER SERIES

\title{
CONSUMPTION TAXES AND ECONOMIC EFFICIENCY IN A STOCHASTIC OLG ECONOMY
}

\author{
Shinichi Nishiyama \\ Kent Smetters \\ Working Paper 9492 \\ http://www.nber.org/papers/w9492 \\ NATIONAL BUREAU OF ECONOMIC RESEARCH \\ 1050 Massachusetts Avenue \\ Cambridge, MA 02138 \\ February 2003
}

Helpful comments were received from Ken Judd and participants at the Stanford Institute for Theoretical Economics, July 2002. The analysis and conclusions expressed in them are those of the authors and should not be interpreted as those of the Congressional Budget Office. The views expressed herein are those of the authors and not necessarily those of the National Bureau of Economic Research.

(C2003 by Shinichi Nishiyama and Kent Smetters. All rights reserved. Short sections of text not to exceed two paragraphs, may be quoted without explicit permission provided that full credit including notice, is given to the source. 
Consumption Taxes and Economic Efficiency in a Stochastic OLG Economy

Shinichi Nishiyama and Kent Smetters

NBER Working Paper No. 9492

February 2003

JEL No. H0, H2, H3

\section{$\underline{\text { ABSTRACT }}$}

Fundamental tax reform is examined in a heterogeneous overlapping-generations (OLG) model in which agents face idiosyncratic earnings shocks and uncertain life spans. Following Auerbach and Kotlikoff (1987), a Lump-Sum Redistribution Authority is used to rigorously examine efficiency gains over the transition path. A progressive income tax is replaced with a flat consumption tax (for example, a value-added tax or a national retail sales tax). If shocks are insurable (that is, no risk), this reform improves (interim) efficiency, a result consistent with the previous literature. But if, more realistically, shocks are uninsurable, this reform reduces efficiency, even though national wealth and output increase over the entire transition path. This efficiency loss, in large part, stems from reduced intragenerational risk sharing that was previously provided by the progressive tax system.

Shinichi Nishiyama

Congressional Budget Office

Ford House Office Building, 4th Floor

Second and D Streets, SW

Washington, DC 20515-6925

shinichi.nishiyama@cbo.gov
Kent Smetters

The Wharton School \& NBER

3641 Locust Walk, CPC 302

Philadelphia, PA 19104-6218

and NBER

smetters@wharton.upenn.edu 


\section{Introduction}

The potential economic benefits from replacing the current income tax system with a flat (proportional) consumption tax system have generated a considerable amount of attention in recent years. Examples of a flat consumption tax include a value-added tax (VAT) in many European nations as well as a national retail sales tax that is gaining attention in the United States as a possible substitute tax base. Replacing the current income tax system with a revenue-neutral flat consumption tax would (i) flatten tax rates, (ii) tax consumption rather than wage and capital income, and (iii) eliminate all tax-base reductions (preferences) contained in current law. In all likelihood, this reform would significantly increase national saving and output over the long run (Altig and others, 2001), a result that we confirm. This paper examines whether this reform actually improves economic efficiency.

Judging the economic efficiency of a particular policy reform has always been important to economists, but it is important to remind ourselves why. Many different policy reforms can, for example, increase the welfare of people born in a long-run steady state, but those gains might simply represent losses to intermediate generations. (Indeed, this point has gained a considerable amount of attention in the recent debate on Social Security privatization.) If there is no economic gain after fully compensating intermediate generations who otherwise lose from reform, then judgments over a reform must be made purely on a philosophical a priori basis ${ }^{1}$ or based on subjective intragenerational and intergenerational distribution choices. ${ }^{2}$ To be sure, economists contribute in important ways to these debates, especially on distributional issues. For example, economists have estimated the impact that a particular tax system has on the distribution of income or wealth within generations (Auerbach and Hassett, 2001) or between generations (Auerbach, Gokhale, and Kotlikoff, 1994). Economists have also derived the implied optimal tax schedules under an assumed social welfare function that weights the utility of different people in a particular way (Mirrlees, 1971). But economists are not particularly better qualified in making philosophical or moral

\footnotetext{
${ }^{1}$ For example, the philosopher Thomas Hobbes argued that it is a priori "wrong" to tax estates on the basis that wealth was already taxed when earned. Others have argued that it is a priori "wrong" for the government to take money from one generation to give to another.

${ }^{2}$ For example, in terms of intragenerational distribution, the philosopher John Rawls argued that social welfare must be judged on the basis of the utility of the worse-off person in society.
} 
judgments than noneconomists. Ultimately, what economists bring to the table in policy debates is our insight about efficiency, interpreted here in the Pareto sense.

The point of departure of our paper is that previous analyses of fundamental tax reform have not incorporated the intragenerational risk-sharing benefits of the current progressive income tax system. Our main finding is that this risk sharing is important for determining the efficiency changes associated with tax reform, even at modest levels of risk aversion. When idiosyncratic earnings shocks are assumed to be fully insurable so that each agent faces no risk, moving to a flat consumption tax increases efficiency, a common result in the literature. However, when wages are uninsurable, efficiency is reduced by moving to a flat consumption tax, even though national wealth and output increase over the entire transition path. ${ }^{3}$

\subsection{The Ramsey Model}

The simplest way to analyze the impact that a revenue-neutral tax reform has on economic efficiency is with the Ramsey infinite-horizon representative-agent model, which assumes that households are Ricardian. Since, in general, efficiency changes are always calculated relative to compensated changes, the presence of a single agent in the Ramsey model dramatically simplifies these calculations. In particular, calculating efficiency changes does not require redistributing resources across agents in order to compensate those who would otherwise lose from reform. As a result, one can often derive the most efficient long-run tax structure analytically (see the reviews by Judd, 1999, and Auerbach and Hines, 2001). But the Ramsey model is less suitable for capturing the intragenerational risk-sharing benefits of a progressive income tax system, which is the focus of the current paper. ${ }^{4}$

\footnotetext{
${ }^{3}$ This paper examines policy changes rather than attempting to derive optimal progressive tax schedules in the Mirrlees tradition where a social welfare function must be assumed. However, our results on the importance of risk sharing would also be relevant to that literature, which, thus far, has found little cause for progressive tax schedules. Although computational considerations limit our ability to derive optimal progressive tax schedules in our model, this extension could prove useful in the future as computers become more powerful.

${ }^{4}$ Well-known complications arise when attempting to model multiple infinite-horizon agents. If agents have identical time preferences (which, realistically, is a measure of zero), then there is an infinite number of wealth distributions compatible with a steady state. If, more realistically, agents have nonidentical time preferences, then the wealth distribution becomes trivial (one agent owns everything). Incorporating progressive tax rates creates additional problems.
} 


\subsection{The Stochastic OLG Model with Finite Horizons}

Instead, this paper uses a calibrated overlapping-generations (OLG) life-cycle model with uninsurable idiosyncratic earnings shocks, uncertain life spans, and elastic labor supply to examine the efficiency gains associated with adopting a revenue-neutral flat consumption tax. The multiplicity of agents, though, complicates the efficiency calculations since tax reform redistributes resources across different households. To deal with this problem, we follow the pioneering work done by Auerbach and Kotlikoff (1987), who developed the first largescale OLG model without uncertainty. Like theirs, our model incorporates a "Lump-Sum Redistribution Authority" (LSRA) that calculates the overall efficiency gains or losses of a policy change, by restoring the utility of the agents alive at the time of the reform to their prereform levels through lump-sum redistributions both across and within generations. We believe that our model is the first large-scale stochastic OLG model to rigorously calculate efficiency gains associated with a fiscal policy reform.

A heuristic technique for calculating efficiency gains that is more common in the literature simply sums welfare changes across households (discounted if across time); a policy is then deemed to increase [decrease] efficiency if the net sum is positive [negative]. This latter approach implicitly assumes that lump-sum transfers are made across households in order to compensate the losers of policy reform with some of the gains of the winners. But this approach fails to capture the price effects associated with these lump-sum transfers.

\subsection{Progressive Consumption Taxes}

While flattening tax rates receives the bulk of the attention in the tax reform debate, consumptionbased taxes can also be progressive. In particular, allowing firms to deduct their full investment expenses at the time of purchase from their tax payments ("full expensing") would effectively produce a consumption tax..$^{5}$ This approach would also allow for some progressivity through either a standard deduction, as in the "flat tax" plan (Hall and Rabushka, 1995), and/or progressive tax rates, as in the "X tax" plan (Bradford, 1986). The "flat tax" and "X tax" plans also protect housing wealth. By maintaining progressive tax rates, the "X tax," in particular, could increase efficiency in our model. Moreover, additional social safety net

\footnotetext{
${ }^{5}$ In fact, a flat consumption tax produces the same outcomes as a flat income tax with full expensing.
} 
programs could potentially substitute for insurance contained in the prereform progressive income tax system to maintain efficiency along with growth effects.

The current paper, though, focuses mainly on a flat consumption tax for several reasons. First, we are more interested in understanding the risk-sharing properties of the current income system than in analyzing specific reform proposals. Second, the computation requirements of our model are already significant. In order to capture the differential tax treatment of various capital items under the "flat tax" and the "X tax," we would have to include housing wealth and other types of capital under separate capital categories. While this addition is possible in deterministic models (Fullerton and Rogers, 1993; Jorgenson and Yun, 2001), adding housing wealth to our stochastic model would alone increase the computation time by two orders of magnitude, requiring about three months to solve a single simulation on a two-gigahertz Pentium IV computer. So we leave this innovation to future research. Third, a national retail sales tax is gaining considerable attention in the United States.

Later in the paper, we do, however, consider a simple progressive consumption tax in the form of a national sales tax with a rebate of the first $\$ 20,000$ of consumption per household. This reform is similar to the "flat tax" proposal except that we don't protect existing housing wealth; our version of the "flat tax," therefore, creates more potential for efficiency gains.

\subsection{Outline}

The outline of our paper is as follows. Section 2 gives a primer on the economic factors associated with moving to a flat consumption tax using a simple two-period model. Section 3 outlines our large-scale model that we use to simulate the introduction of a revenue-neutral flat consumption tax. Section 4 summarizes the calibration of the baseline economy. Section 5 explains the Lump-Sum Redistribution Authority. Section 6 outlines a deterministic version of our model that allows us to make comparisons with the stochastic version. Section 7 reports the results of policy experiments. Section 8 concludes. The appendix describes the computational algorithm in detail. 


\section{A Primer on Tax Reform}

This section uses a simple partial-equilibrium model to present a brief overview of tax reform in an OLG economy. We first consider tax reform in which the prereform income tax system is linear and the economy is deterministic. We then expand the discussion to the presence of nonlinear taxes in the prereform economy, and then finally to uncertainty in the form of idiosyncratic wage shocks and life spans. We do not consider the effects of removing tax preferences; this issue and others are addressed in our larger-scale model, which is presented in the next section.

\subsection{No Uncertainty, Linear Taxes}

\subsubsection{The Prereform Economy}

Consider a simple two-period model in which agents work during the first period and retire in the second period. During the first period, an agent born in time $t$ earns pretax wages $w_{1, t}$, pays a wage tax at rate $\tau_{t}^{w}$, consumes $c_{1, t}$, and saves the remainder as assets, $a_{2, t+1}$, in order to afford second-period consumption. During period two at time $t+1$, the agent's consumption, $c_{2, t+1}$, is equal to $a_{2, t+1}$ plus net interest paid at time $t+1, r_{t+1}$, after paying a capital income tax at rate $\tau_{t}^{r}$. The agent's budget constraints, therefore, are as follows:

$$
\begin{aligned}
& c_{1, t}+a_{2, t+1}=\left(1-\tau_{t}^{w}\right) w_{1, t}, \\
& c_{2, t+1}=\left[1+\left(1-\tau_{t+1}^{r}\right) r_{t+1}\right] a_{2, t+1} .
\end{aligned}
$$

A linear income tax, $\tau_{t}^{y}$, is created by setting $\tau_{t}^{r}=\tau_{t}^{w}=\tau_{t}^{y}$. Assuming that there are no borrowing constraints (or, alternatively, $a_{2, t+1} \geq 0$ ), the household's lifetime budget constraint equals

$$
c_{1, t}+\frac{c_{2, t+1}}{\left[1+\left(1-\tau_{t+1}^{r}\right) r_{t+1}\right]}=\left(1-\tau_{t}^{w}\right) w_{1, t} .
$$

We can rewrite equation (1) as

$$
\frac{c_{1, t}}{1-\tau_{t}^{w}}+\frac{c_{2, t+1}}{\left[1+\left(1-\tau_{t+1}^{r}\right) r_{t+1}\right]\left(1-\tau_{t}^{w}\right)}=w_{1, t}
$$

or

$$
\left(1+\tilde{\tau}_{1, t}^{c}\right) c_{1, t}+\frac{\left(1+\tilde{\tau}_{2, t+1}^{c}\right) c_{2, t+1}}{\left(1+r_{t+1}\right)}=w_{1, t},
$$


where $\tilde{\tau}_{1, t}^{c} \equiv \frac{1}{1-\tau_{t}^{w}}-1$ and $\tilde{\tau}_{2, t+1}^{c} \equiv \frac{1+r_{t+1}}{\left[1+\left(1-\tau_{t+1}^{r}\right) r_{t+1}\right]\left(1-\tau_{t}^{w}\right)}-1$. Hence, a system of linear wage taxes, capital income taxes, and income taxes can be represented in terms of equivalent age-indexed effective consumption tax rates, $\tilde{\tau}^{c}$. (The tilde [ ] superscript is used to denote effective rates.) Both tax systems collect the same lifetime present value of taxes from each agent and offer the same incentives.

Notice that if tax rates are stationary then $\tilde{\tau}_{2}^{c}>\tilde{\tau}_{1}^{c}$ when $\tau_{t+1}^{r}>0$, that is, a positive capital income tax increases the effective consumption tax rate over the life cycle. By the inverse-elasticity rule of the optimal tax literature, this increasing tax rate is a potential source of inefficiency unless the price elasticity of second-period consumption is lower relative to first-period consumption, a result that is not an implication of most specifications of household preferences. A key motivation for tax reform, as discussed below, is to remove this potential distortion.

Government revenue each period finances a fixed level of spending, $\bar{G}$ :

$$
\tau_{t}^{w} w_{1, t}+\tau_{t}^{r} r_{t} a_{2, t}=\bar{G}
$$

where the population size is assumed to be stationary. ${ }^{6}$

\subsubsection{Postreform Economy: A Revenue-Neutral Consumption Tax}

Now suppose that the government introduces a consumption tax, $\tau_{t}^{c}$, at time $t$ to replace the income tax. The private budget constraints become

$$
\begin{aligned}
& \left(1+\tau_{t}^{c}\right) c_{1, t}+a_{2, t+1}=w_{1, t}, \\
& \left(1+\tau_{t+1}^{c}\right) c_{2, t+1}=\left[1+r_{t+1}\right] a_{2, t+1},
\end{aligned}
$$

which produces the following lifetime budget constraint:

$$
\left(1+\tau_{t}^{c}\right) c_{1, t}+\frac{\left(1+\tau_{t+1}^{c}\right) c_{2, t+1}}{\left(1+r_{t+1}\right)}=w_{1, t} .
$$

The government's budget constraint equals

$$
\tau_{t}^{c}\left(c_{1, t}+c_{2, t}\right)=\bar{G} .
$$

\footnotetext{
${ }^{6}$ Equation (3) could also be represented in terms of the effective consumption tax rates shown above. However, when analyzing a tax reform, which changes the present value of taxes paid by each generation, equation (3) is needed in its current form because second-period agents alive at the reform did not actually face the effective consumption tax $\tilde{\tau}_{1}^{c}$ during their first period of life.
} 


\subsubsection{Primary Tax Effects of Adopting a Revenue-Neutral Consumption Tax}

When the prereform tax system is linear, the adoption a revenue-neutral consumption tax can be decomposed into two sequential steps:

i. Replace the linear income tax with a linear wage tax, thereby removing the tax on capital income.

ii. Replace this new linear wage tax with a consumption tax, thereby imposing a lumpsum tax on existing assets.

Since we regard the second step as occurring immediately after the first step, the ageasset profile in the prereform economy is the one that is relevant for determining the impact of the lump-sum tax on existing assets. ${ }^{7}$

i) Removing the Tax on Capital Income. Comparing equations (1) and (4), notice that this tax reform generates uniform consumption tax rates across the life cycle in a stationary economy since capital income is no longer taxed. As a result, the intertemporal price distortion is removed, encouraging saving. If labor supply were also elastic, an increase in after-tax interest rates would encourage more labor supply and saving earlier in the life cycle since asset values would accumulate more quickly.

However, this good news does not come for free. The assets that have already been accumulated by generation $(t-1)$ at time $t$, which would have been taxed under the original income tax, will not be taxed after the reform. So generation $(t-1)$ receives a lump-sum transfer (negative tax) equal to $\tau_{t}^{r} r_{t} a_{2, t}$, which must be paid by future workers in the form of wage taxes in order to make up the lost revenue. ${ }^{8}$ Moreover, because the wage base is smaller than the income base, tax rates increase. Since tax distortion increases with the square of the tax rate, a smaller tax base will produce more distortions. In the finite-horizons OLG model,

\footnotetext{
${ }^{7}$ In static models with one or two periods (and no bequests), one could alternatively distinguish between the tax reform's "substitution effect" and "income effect." However, this distinction is substantially more cumbersome in a model with more than two periods where some agents have accumulated wealth by the time of the reform and will also live for more than one additional period after the reform. See Gravelle (2002) for a detailed critique of intertemporal models.

${ }^{8}$ Our simple two-period model, though, somewhat exaggerates this point by taxing capital income only at the beginning of the second period. With multiple periods, asset holders will have already paid some taxes on capital income before the tax reform.
} 
these new distortions could, in theory, outweigh the gains associated with removing the intertemporal price distortion. In fact, in their simulation analysis using a multiple-period deterministic model with elastic labor supply, Auerbach and Kotlikoff (1987) find that replacing a linear income tax with a linear wage tax reduces long-run output and welfare. ${ }^{9}$

ii) Imposing a Lump-Sum Tax on Existing Wealth. As demonstrated by Summers (1981), adopting a consumption tax also imposes a lump-sum tax on older people. In particular, the consumption by generation $(t-1)$ in their second period of life is inelastic at time $t$ since their consumption is based on previous saving. Hence, when the government changes the tax system at time $t$, these agents face a lump-sum tax equal to $\tau_{t}^{c} c_{2, t}$, which, under revenue neutrality, accrues as reduced taxes paid by future workers. ${ }^{10}$

In fact, the lump-sum tax on generation $(t-1)$ accrues as a reduced tax liability to all future generations. To demonstrate this fact, suppose that agents only consume during the second period of their lives (that is, $\left.c_{1, t}=0\right)$ and taxes on interest are zero $\left(\tau^{r}=0\right)$ so that only wages are taxed. ${ }^{11}$ Under these assumptions, wage and consumption taxes are lump sum for all generations, allowing for easy illustration. Now suppose that the government switches tax bases from wages to consumption at time $t$. Generation $(t-1)$, which is in their second period of life when the tax reform occurs, is charged a wealth levy equal to $\bar{G}$. Clearly, they are worse off - they paid $\bar{G}$ during their first period of life under the previous wage tax, and now they must pay it again during their second period under the new consumption tax. Now consider generation $t$, which is in their first period of life when taxes are reformed. Under the former wage tax, generation $t$ would have paid $\bar{G}$ during their first period of life. Instead, they now pay $\bar{G}$ in their second period, reducing the present value of their lifetime taxes by $\left(\bar{G}-\frac{\bar{G}}{1+r}\right)$, or $r \bar{G} /(1+r)$. Similarly, every future generation $s(s>t)$ receives a present-value reduction in their tax liability equal to $r \bar{G} /(1+r)$, calculated with respect to their generation index, $s$. The present value sum of tax saving across all future generations, calculated at time $t$, therefore, equals $\sum_{i=0}^{\infty} \frac{(r \bar{G} /(1+r))}{(1+r)^{i}}=\bar{G}$. In other words, the present value

\footnotetext{
${ }^{9}$ In contrast, the optimal long-run tax rate on capital income is zero in the Ramsey model.

${ }^{10}$ As noted in the previous section, a flat consumption tax produces the same outcomes as a flat income tax with full expensing. Under expensing, the lump-sum tax on existing wealth takes the form of a fall in Tobin's q, as old capital becomes less valuable relative to new capital.

${ }^{11}$ See also Auerbach and Kotlikoff (1987, pp. 58 - 59).
} 
of the tax reduction to future generations exactly equals the loss to the initial elderly.

This intergenerational transfer has a very powerful impact on long-run output and welfare. Auerbach and Kotlikoff find that replacing a linear income tax with a flat consumption tax increases long-run output and welfare. Why are the results so different in the AK model relative to the wage tax base discussed above? The reason is the wealth levy on the existing capital held by generation $(t-1)$ that occurs with a consumption tax but not with a wage tax; in fact, this wealth levy is the only difference between those two tax bases. In the case of a consumption tax, this wealth levy extracts enough resources to reduce future tax burdens, producing a long-run gain. In fact, over 100 percent of the long-run gain in the AK model stems from this wealth levy (Engen, Gravelle, and Smetters, 1997).

\subsubsection{Total Efficiency Gains}

It is important, though, to distinguish between redistribution and efficiency. In the previous two-period example, replacing the linear wage tax with a consumption tax would produce a sizable long-run increase in the capital stock and output. But this entire gain comes off the backs of generation $(t-1)$. In other words, if generation $(t-1)$ were to receive a lump-sum rebate equal to $\bar{G}$ so that its utility is held fixed, future generations would no longer benefit from tax reform. Hence, the efficiency gain is exactly zero despite the large long-run gains. Recall, though, two key assumptions that we made: (i) agents lived for only two periods, and (ii) all taxes were effectively lump-sum for all generations. Not surprisingly, therefore, tax reform produces zero efficiency gains.

In a more realistic setting with more than two periods and with consumption in each period, replacing a linear income tax with a consumption tax would probably produce efficiency gains. To be sure, removing the tax on capital income alone has an unclear impact on efficiency since the benefit from removing the intertemporal price distortion must be balanced against the higher tax rate. However, the lump-sum tax on existing assets is likely to lead to sizable efficiency gains inside a multiperiod model. The reason is that, after controlling for intergenerational redistribution, agents with assets who are alive at the time of the reform benefit from replacing some of their own future distorting taxes with the lump-sum taxes that 
they pay today in the form of a wealth levy. ${ }^{12}$ Accounting for these different effects requires simulation analysis. Auerbach and Kotlikoff find that efficiency is increased by replacing a linear income tax with a linear consumption tax in a deterministic framework. Within the Ramsey model, many previous papers have also found positive gains from adopting a consumption tax (see the review in Stokey and Rebelo, 1995).

\subsection{No Uncertainty, Nonlinear Taxes}

\subsubsection{Prereform Economy}

With nonlinear tax rates in the prereform economy, the agent's budget constraints are

$$
\begin{aligned}
& c_{1, t}+a_{2, t+1}=w_{1, t}-T_{t}^{w}\left(w_{1, t}\right), \\
& c_{2, t+1}=\left(1+r_{t+1}\right) a_{2, t+1}-T_{t+1}^{r}\left(r_{t+1} a_{2, t+1}\right),
\end{aligned}
$$

where the $T(\cdot)$ functions represent total taxes paid. The average wage tax rate equals $T_{t}^{w}\left(w_{1, t}\right) / w_{1, t}$, which is smaller than the marginal wage tax rate, $\partial T_{t}^{w}\left(w_{1, t}\right) / \partial w_{1, t}$. Similarly, the average and marginal tax rates on capital income are $T_{t+1}^{r}\left(r_{t+1} a_{2, t+1}\right) /\left(r_{t+1} a_{2, t+1}\right)$ and $\partial T_{t+1}^{r}\left(r_{t+1} a_{2, t+1}\right) / \partial\left(r_{t+1} a_{2, t+1}\right)$, respectively.

With a stationary population size, the government's budget constraint is

$$
T_{t}^{w}\left(w_{1, t}\right)+T_{t+1}^{r}\left(r_{t+1} a_{2, t+1}\right)=\bar{G}
$$

\subsubsection{Primary Tax Effects of Adopting a Revenue-Neutral Consumption Tax}

The budget constraints in the postreform economy with a revenue-neutral proportional consumption tax are the same as shown earlier. The introduction of progressive income taxes into the prereform economy, however, alters somewhat the two steps described above, and also adds a third step:

i. Replace the progressive income tax with a progressive wage tax, thereby removing the tax on capital income.

\footnotetext{
${ }^{12}$ We benefited from a helpful conversation with Alan Auerbach on this point.
} 
ii. Replace this new progressive wage tax with a progressive consumption tax, thereby imposing a lump-sum tax on existing assets. ${ }^{13}$

iii. Replace this new progressive consumption tax with a proportional consumption tax, thereby flattening tax rates.

We again think of each step as occurring immediately after the previous step.

i) Removing the Tax on Capital Income. Much of the debate about whether to adopt a consumption tax focuses on removing distortions caused by progressive tax rates. Indeed, progressive tax rates tend to magnify intertemporal distortions. First, even with inelastic labor supply, saving decisions are distorted more with progressive taxes since the future marginal tax rate that a person faces on capital income is now directly affected by their saving decisions. Removing the tax on capital income, therefore, encourages even more saving when the prereform income tax is progressive. Second, allowing for elastic labor supply tends to enhance this result. Marginal income tax rates tend to peak at middle age when labor productivity is high and after a fair amount of assets have been accumulated for retirement. So agents tend to shift their labor supply away from high-tax years in the middle years of life toward lower-tax years later in life. Since more labor income is now earned later in life, less saving is needed earlier in life to smooth consumption. Removing the tax on capital income, therefore, would eliminate those distortions, which tend to be more significant when the prereform income tax is progressive.

As with the linear income tax considered before, however, one must also account for the government's budget constraint. Increasing wage tax rates to make up lost revenue now creates more distortions than in the linear tax case considered earlier. Distortions increase the most if the progressive wage tax schedule is increased in a progressive manner in order to protect the poor. But even if the additional tax burden is distributed in a proportional manner, distortions will rise faster relative to the linear case considered earlier.

\footnotetext{
${ }^{13}$ In practice, this could be achieved with full expensing, discussed in Section 1. An equivalent progressive VAT or sales tax could also be implemented, but would be substantially more cumbersome to administer.
} 
ii) Imposing a Lump-Sum Tax on Existing Wealth As noted earlier, in a multiple-period model, the efficiency gains produced by a lump-sum tax on existing wealth depend on the extent to which lump-sum taxes replace future distorting taxes of those alive at the time of the reform. The more assets held by younger and middle-aged workers at the time of the reform, the more likely the wealth levy produces efficiency gains. Whether, for a given capitaloutput ratio, ${ }^{14}$ these cohorts hold a larger share of capital under progressive taxes depends on the exact model parameters. ${ }^{15}$ Still, the efficiency gains associated with moving to a consumption tax are likely to be much larger when the prereform income tax is progressive since this tax system is more distorting, increasing the value of the substitute lump-sum tax.

iii) Flattening Tax Rates The effect of moving from a progressive consumption tax to a flat consumption tax produces two competing major effects (and a couple minor effects that we'll ignore). First, it removes an important price distortion across the life cycle. Specifically, consumption increases over the life cycle when the interest rate exceeds the rate of time preference. ${ }^{16}$ As a result, marginal consumption tax rates also increase over the life cycle, similar to the pattern produced by a capital income tax considered earlier. A shift to a proportional tax, therefore, creates a uniform tax rate on consumption, removing this intertemporal distortion. Second, this reform gives many asset holders at the time of the reform a lump-sum transfer (negative tax), reducing efficiency.

\subsubsection{Total Efficiency Gains}

On net, there are likely to be sizable efficiency gains from adopting a flat consumption tax when the original income tax system is progressive. Both Auerbach and Kotlikoff (1987), using the OLG model, as well as Jorgenson and Yun (2001), who use the Ramsey model

\footnotetext{
${ }^{14}$ When comparing across models, one should always solve for the deep parameters that generate the same observable economy, including the capital-output ratio. In this way, you ensure that the predictions are not being generated by different calibrations.

${ }^{15}$ Younger workers tend to face lower tax rates under a progressive system, giving them more resources to save. But they also face increasing marginal tax rates in the future as their human capital returns increase, decreasing their incentive to save. Older people, except those who have accumulated lots of wealth, also have a few more resources to reinvest under a progressive tax system. But the intertemporal shift in their labor supply described earlier in the text tends to reduce their saving. Hence, the remaining share held by middle-aged workers also depends on the parameters.

${ }^{16}$ This effect cannot happen in the infinite-horizon model since the interest rate equals the time preference rate in a steady state.
} 
described in Section 1, find large efficiency gains. Later in this paper, we verify this result using a deterministic version of our model introduced in Section 3.

\subsection{Wage and Life-Span Uncertainty, Nonlinear Taxes}

We now consider the addition of wage and life-span uncertainty into the prereform and postreform economies. The budget constraints for the prereform economy are the same as those shown in the previous subsection. Moreover, the budget constraints in the postreform economy do not change either. Adding wage and life-span uncertainty also does not change the three steps of tax reform discussed above. But the addition of uncertainty does influence the analysis associated with each step. We consider each step in turn.

\subsubsection{Primary Tax Effects of Adopting a Revenue-Neutral Consumption Tax}

i) Removing the Tax on Capital Income. The addition of wage uncertainty tends to reduce the importance of price distortions over the life cycle. With inelastic labor supply, agents would hedge their earnings uncertainty by saving in a precautionary manner. ${ }^{17}$ As a result, household saving becomes less responsive to an increase in the after-tax interest rate following a shift to a consumption tax base. ${ }^{18}$ To be sure, with elastic labor supply, the need to save in a precautionary manner is reduced somewhat since agents can, for example, work multiple low-paying jobs in order to replace a former higher-paying job. But since utility is concave in leisure and the maximum leisure time is bounded, the ability to vary working hours cannot eliminate precautionary saving altogether. As a result, saving will be less sensitive to changes in the after-tax interest rate relative to the case without uncertainty. Labor supply, which now serves as partial insurance against bad shocks, also becomes less sensitive to changes in interest rates.

When fair annuities are not available, adding life-span uncertainty produces two competing effects. On the one hand, life-span uncertainty should lead to greater precautionary saving, which decreases the interest elasticity of saving. On the other hand, the horizon of agents is effective "longer" since a prudent agent will plan for a time period longer than

\footnotetext{
${ }^{17}$ Precautionary saving is positive if the third derivative of the agent's felicity function is positive, a condition which holds in our model.

${ }^{18}$ This point was emphasized in Engen and Gale (1996) and Engen, Gravelle, and Smetters (1997).
} 
average. This longer time period might enhance price sensitivity somewhat. ${ }^{19}$ The presence of a Social Security system in our large-scale model (Section 3) will tend to reduce the importance of both of those effects.

ii) Imposing a Lump-Sum Tax on Existing Wealth. While the lump-sum tax on existing wealth following the adoption of a consumption tax has a large impact on efficiency, the introduction of wage and life-span uncertainty itself produces two competing effects. On the one hand, the asset-age profile for the average person is relatively less "hump-shaped" due to greater precautionary saving both earlier in the life cycle (mostly due to earnings uncertaint ${ }^{20}$ ) and later in the life cycle (due to life-span uncertainty). As a result, for a given capital-output ratio, the wealth levy on the young is higher, reducing their future distorting taxes by more than without uncertainty. As noted earlier, the main source of efficiency gains from imposing a lump-sum tax on existing wealth stems from replacing some of the future distorting taxes of agents alive at the time of the reform with lump-sum taxes. The more of a nation's wealth that is held by the young, therefore, the larger the potential efficiency gains. As a result, the introduction of uncertainty into the analysis could potentially increase the efficiency gains after tax reform, provided that the share of assets that are now held by elderly has not increased too much relative to the case without uncertainty. On the other hand, the value of a lump-sum tax on wealth is not as large as without uncertainty due to the reduced importance of distortions, discussed above. Simulation analysis, therefore, is required for determining the net effect.

\footnotetext{
${ }^{19}$ The interaction of life-span uncertainty with wage uncertainty, though, complicates matters. For example, if in the extreme, agents lived forever with certainty, we would be back in the infinite-horizons world where we would want to focus on a single agent. In this case, Aiyagari (1995) demonstrates that the optimal tax rate on capital income would actually be positive when the infinitely lived agent faces uninsurable idiosyncratic earnings shocks. Intuitively, elastic labor supply prevents the government from employing confiscatory wage taxes to replicate full insurance. As a result, precautionary saving drives the interest rate below the agent's rate of time preference, generating too much capital in the economy relative to the modified golden rule. A positive capital income tax brings the economy's level of capital back to the efficient level. The Aiyagari motive for a positive capital income tax rate, though, is not present in a stochastic finite-horizon OLG model — not even as an approximation - unless precautionary saving produces enough capital so that the economy becomes dynamically inefficient. Whereas dynamic inefficiency is guaranteed in Aiyagari's model (where the actual level of capital is compared against the modified golden rule level of capital), it is not in a finite-horizon OLG model (where the comparison is made with the golden rule level of capital).

${ }^{20}$ Since labor supply is now partly a self-insurance mechanism, people are also less likely in the prereform economy to take advantage of falling future marginal tax rates by postponing their labor supply, thereby generating more saving earlier in life.
} 
iii) Flattening Tax Rates. When uncertainty is added to the model, flattening the tax rates reduces risk sharing within generations. The reason is that the prereform progressive tax system shares idiosyncratic earnings shocks. A switch to a flat tax system reduces (but does not eliminate ${ }^{21}$ ) this risk sharing, generating an increase in precautionary saving following tax reform. Indeed, it is ambiguous a priori whether the addition of uncertainty reduces or increases the saving response to tax reform when the prereform tax system is progressive, even though uncertainty reduces the saving response to changes in the after-tax interest rate.

By reducing risk sharing, flattening tax rates might represent a nontrivial source of efficiency losses. In fact, if labor supply were completely inelastic (or perfectly observable by the government, as with first-best taxes) then all agents in identical states (that is, same assets; same current-period wage income; same age; and so on) would want to fully share future wage shocks. In this case, the most efficient tax on consumption would be extremely progressive: consumption levels above these individuals' expectation (that is, state-contingent expectation) would be taxed at 100 percent while consumption below average would be taxed at a negative rate (subsidized) so that it equaled the expected outcome.

In reality, of course, the most efficient second-best progressive tax system will not fully share all future risks. First, labor supply is obviously not completely inelastic. In essence, agents with greater-than-expected wage realizations will distort their future labor supply in order to partially "renege" on the previous risk-sharing "agreement." Since this incentive is understood ex ante, the optimal tax schedule cannot fully share risks ex post. Second, in realistic tax systems, taxes paid by any agent in a given year depend only on the agent's current state and not on that agent's state in previous years. As a result, a progressive tax system will redistribute resources in the future across agents at different states today. With elastic labor supply, this "extra" redistribution is a source of (interim) inefficiency. ${ }^{22}$

\footnotetext{
${ }^{21}$ To some extent, even a linear tax shares risks since people with higher earnings realizations pay more taxes. But progressive taxes share those risks even more.

${ }^{22}$ In our analysis, we focus on "interim" efficiency, where the expected remaining lifetime utility of living agents is calculated conditional on their current state at the time of reform, and the expected utility of future generations is calculated conditional on the initial state into which they are "born" as independent economic actors. If we instead measured expected utility across all possible states (the so-called "ex ante" position), our results regarding the importance of risk sharing would only be strengthened.
} 


\subsubsection{Total Efficiency Gains}

The remainder of this paper examines the importance of wage and life-span uncertainty when analyzing tax reform. Since closed-form solutions are not possible in assessing these different competing forces, we use simulation analysis to help determine the impact on efficiency from replacing a progressive income tax system with a flat consumption tax. The next section lays out the computation model that we use.

\section{Model}

The economy consists of three main sectors: heterogeneous households with elastic labor supply; a perfectly competitive representative firm with constant-returns-to-scale production technology; and a government with a full commitment technology. ${ }^{23}$

\subsection{The Household Sector}

Households are heterogeneous with respect to age $i$, working ability $e_{i}$ (measured by its hourly wage), beginning-of-period wealth holding $a_{i}$, and average historical earnings $b_{i}$ that is used to determine Social Security benefits. Every year, a large number (normalized to unity) of new households of age 20 enter into the economy. ${ }^{24}$ A household of age $i$ observes idiosyncratic working ability shock, $e_{i}$, at the beginning of each year and chooses its optimal consumption $c_{i}$, working hours $h_{i}$, and end-of-period wealth holding $a_{i+1}$, taking the government's policy schedule and a series of factor prices and the government's policy variables as given. ${ }^{25}$ At the end of each year, a fraction of households die. Households are alive at most up to 109 years old, and the mortality rate at the end of age 109 is one. Tables 1 and 2 show the main variables and functions used in the household's problem.

\footnotetext{
${ }^{23} \mathrm{As}$ is standard in the optimal tax literature, we assume that the government can commit to future policies, thereby ignoring time-consistency issues.

${ }^{24}$ The population of this economy is normalized by the constant population growth rate $\nu$.

${ }^{25}$ Because there are no aggregate shocks in the present model, the policy variables and factor prices of rational expectation are actually ones of perfect foresight. But agents do not know their own future wages and life spans.
} 
Table 1: Main Variables and Functions in the Model

\begin{tabular}{lll}
\hline Individual state: & $\mathbf{s}_{i}=\left(i, e_{i}, a_{i}, b_{i}\right)$ & \\
$i$ & $\in I=\{20, \ldots, 109\}$ & Age \\
$e_{i}$ & $\in E=\left[e^{\min }, e^{\max }\right]$ & Working ability (hourly wage) \\
$a_{i}$ & $\in A=\left[a^{\min }, a^{\max }\right]$ & Beginning-of-period wealth \\
$b_{i}$ & $\in B=\left[b^{\min }, b^{\max }\right]$ & Average historical earnings (AIME×12)
\end{tabular}

Aggregate state: $\mathbf{S}_{t}=\left(x_{t}\left(\mathbf{s}_{i}\right), W_{g, t}\right)$

$x_{t}\left(\mathbf{s}_{i}\right)$

Joint distribution of households ${ }^{(b)}$

$W_{g, t}$

Beginning-of-period government wealth ${ }^{(\mathrm{c})}$

Policy schedule and rule: $\Psi_{t}=\left\{W_{g, s+1}, C_{g, s}, \tau_{I, s}(.), \tau_{P, s}(.), \tau_{C, s}, \operatorname{tr}_{S S, s}(.)\right\}_{s=t}^{\infty}$

$W_{g, s+1} \quad$ End-of-period government wealth ${ }^{(\mathrm{c})}$

$C_{g, s} \quad$ Government consumption ${ }^{(\mathrm{c})}$

$\tau_{I, s}($.$) \quad Federal income tax function { }^{(\mathrm{d})}$

$\tau_{P, s}($.$) \quad Payroll tax function { }^{(\mathrm{d})}$

$\tau_{C, s} \quad$ Consumption tax rate

$\operatorname{tr}_{S S, s}($.$) \quad Social Security benefit function { }^{(\mathrm{d})}$

Household decision rules: $\mathbf{d}\left(\mathbf{s}_{i}, \mathbf{S}_{t} ; \mathbf{\Psi}_{t}\right)=\left(c_{i}(),. h_{i}(),. a_{i+1}().\right)$

$c_{i}($.

$h_{i}($.

$a_{i+1}($.

Main parameters and other variables

\begin{tabular}{lll}
$\beta$ & $\in \mathbf{R}_{+}$ & Time preference $(\mathrm{e})$ \\
$\phi_{i}$ & $\in[0,1]$ & \\
$\mu$ & $\in \mathbf{R}$ & Survival rate at the end of age $i$ \\
$\nu$ & $\in \mathbf{R}$ & Labor augmenting productivity growth rate \\
$w_{t}$ & $\in \mathbf{R}_{+}$ & Population growth rate \\
$r_{t}$ & $\in \mathbf{R}$ & Wage rate (1.0 in the baseline) \\
$q_{t}$ & $\in \mathbf{R}_{+}$ & Interest rate \\
\hline
\end{tabular}

(a) These variables are adjusted by the steady-state (per capita) economic growth rate.

(b) The measure of households is adjusted by the steady-state population growth rate.

(c) The government's net wealth and most aggregate variables (shown below) are adjusted by the steady-state economic growth rate and population growth rate.

(d) The arguments of these functions are adjusted by the steady-state economic growth rate. Time invariant tax and benefit functions imply that the actual schedules are adjusted so that there is no real bracket creep whenever the economy is on the balanced growth path.

(e) The time preference parameter is adjusted by the steady-state economic growth rate. The adjustment depends on the specification of the utility function. 
Table 2: Other Aggregate Variables in the Model

\begin{tabular}{lll}
\hline$W_{t}$ & $\in \mathbf{R}_{+}$ & National wealth \\
$L_{t}$ & $\in \mathbf{R}_{+}$ & Total labor supply \\
$K_{t}$ & $\in \mathbf{R}_{+}$ & Capital stock \\
$Y_{t}$ & $\in \mathbf{R}_{+}$ & Gross national product \\
$T_{I, t}$ & $\in \mathbf{R}$ & Federal income tax revenue \\
$T_{P, t}$ & $\in \mathbf{R}$ & Federal payroll tax revenue \\
$T_{C, t}$ & $\in \mathbf{R}$ & Federal consumption tax revenue \\
$T_{S S, t}$ & $\in \mathbf{R}$ & Total OASDI benefits \\
\hline
\end{tabular}

Note: All aggregate variables are adjusted by the steady-state economic growth and population growth; that is, these variables in the model stay at the same level when the economy is on the balanced growth path.

\subsubsection{The Household's Problem}

Let $\mathbf{s}_{i}$ denote the individual state vector of an age $i$ household, let $\mathbf{S}_{t}$ denote the aggregate state vector at the beginning of year $t$, and let $\Psi_{t}$ denote the series of government policy rules known at the beginning of year $t$,

$$
\begin{aligned}
& \mathbf{s}_{i}=\left(i, e_{i}, a_{i}, b_{i}\right), \\
& \mathbf{S}_{t}=\left(x_{t}(.), W_{g, t}\right), \\
& \mathbf{\Psi}_{t}=\left\{W_{g, s+1}, C_{g, s}, \tau_{I, s}(.), \tau_{P, s}(.), \tau_{C, s}, \operatorname{tr}_{S S, s}(.)\right\}_{s=t}^{\infty} .
\end{aligned}
$$

Then, the value function of a household is

$$
v\left(\mathbf{s}_{i}, \mathbf{S}_{t} ; \mathbf{\Psi}_{t}\right)=\max _{c_{i}, h_{i}, a_{i+1}} u_{i}\left(c_{i}, h_{i}\right)+\beta \phi_{i} E\left[v\left(\mathbf{s}_{i+1}, \mathbf{S}_{t+1} ; \mathbf{\Psi}_{t+1}\right) \mid e_{i}\right]
$$

subject to

$$
\begin{gathered}
a_{i+1}=\frac{1}{1+\mu}\left\{w_{t} e_{i} h_{i}+\left(1+r_{t}\right) a_{i}-\tau_{I, t}\left(w_{t} e_{i} h_{i}, r_{t} a_{i}, \operatorname{tr}_{S S, t}\left(i, b_{i}\right)\right)\right. \\
\left.-\tau_{P, t}\left(w_{t} e_{i} h_{i}\right)+\operatorname{tr}_{S S, t}\left(i, b_{i}\right)-\left(1+\tau_{C, t}\right) c_{i}\right\} \geq a^{\min }
\end{gathered}
$$

and $a_{20}=0, a_{110} \geq 0 .^{26}$

\footnotetext{
${ }^{26}$ Alternatively, we can use $\boldsymbol{\Psi}_{t}$ for $\boldsymbol{\Psi}_{t+1}$ on the right-hand side of the objective function because $\boldsymbol{\Psi}_{t}$ includes the information of $\boldsymbol{\Psi}_{t+1}$.
} 
Let $\pi_{i, i+1}\left(e_{i+1} \mid e_{i}\right)$ be the conditional probability for the age $i+1$ working ability being $e_{i+1}$ when the age $i$ working ability is $e_{i} .{ }^{27}$ Then,

$$
E\left[v\left(\mathbf{s}_{i+1}, \mathbf{S}_{t+1} ; \mathbf{\Psi}_{t+1}\right) \mid e_{i}\right]=\int_{E} v\left(\mathbf{s}_{i+1}, \mathbf{S}_{t+1} ; \mathbf{\Psi}_{t+1}\right) \pi_{i, i+1}\left(e_{i+1} \mid e_{i}\right) \mathrm{d} e_{i+1} .
$$

At the beginning of the next period, the individual state, the aggregate state, and the government policy rules become

$$
\begin{aligned}
& \mathbf{s}_{i+1}=\left(i+1, e_{i+1}, a_{i+1}+q_{t}, b_{i+1}\right) \quad \text { with } \pi_{i, i+1}\left(e_{i+1} \mid e_{i}\right), \\
& \mathbf{S}_{t+1}=\left(x_{t+1}(.), W_{g, t+1}\right), \\
& \mathbf{\Psi}_{t+1}=\left\{W_{g, s+1}, C_{g, s}, \tau_{I, s}(.), \tau_{P, s}(.), \tau_{C, s}, \operatorname{tr}_{S S, s}(.)\right\}_{s=t+1}^{\infty},
\end{aligned}
$$

where $W_{g, t+1}$ is determined by the government budget constraint. A household's retrospective average earnings for Social Security purposes are

$$
b_{i+1}= \begin{cases}0 & \text { if } i \leq 24 \\ \frac{1}{i-24}\left\{(i-25) b_{i} \frac{w_{t}}{w_{t-1}}+\min \left(w_{t} e_{i} h_{i} / 2, w e h_{t}^{\max }\right)\right\} & \text { if } 25 \leq i \leq 59 \\ (1+\mu)^{-1} b_{i} & \text { if } i \geq 60\end{cases}
$$

where $w e h_{t}^{\max }$ is the threshold, which is $\$ 80,400$ in 2001 . For simplicity, we assume that the highest 35 years of earnings correspond to those years of age between 25 and $59 .{ }^{28}$

The decision rule of an age $i$ household in year $t$ is a function of its individual state $\mathbf{s}_{i}$, the aggregate state $\mathbf{S}_{t}$, and the government policy rules $\Psi_{t}$, and is shown as

$$
\mathbf{d}\left(\mathbf{s}_{i}, \mathbf{S}_{t} ; \mathbf{\Psi}_{t}\right)=\left\{c_{i}\left(\mathbf{s}_{i}, \mathbf{S}_{t} ; \mathbf{\Psi}_{t}\right), h_{i}\left(\mathbf{s}_{i}, \mathbf{S}_{t} ; \mathbf{\Psi}_{t}\right), a_{i+1}\left(\mathbf{s}_{i}, \mathbf{S}_{t} ; \boldsymbol{\Psi}_{t}\right)\right\}
$$

\subsection{The Measure of Households}

Let $x_{t}\left(\mathbf{s}_{i}\right)$ denote the measure of households, and let $X_{t}\left(\mathbf{s}_{i}\right)$ be the corresponding cumulative measure. The measure of households is adjusted by the population growth rate. The

\footnotetext{
${ }^{27}$ Since $e_{i+1}$ is a random variable with conditional probability distribution $\pi_{i, i+1}\left(e_{i+1} \mid e_{i}\right), \mathbf{s}_{i+1}=(i+$ $\left.1, e_{i+1}, a_{i+1}, b_{i+1}\right)$ is a random vector. Hence, $e_{i}$ is a realized number and $\mathbf{s}_{i}$ is a realized vector.

${ }^{28}$ Social Security benefits in the United States are computed on the basis of the highest 35 years of earnings, adding an additional state variable to our model. Earnings before age 60 are wage indexed, and earnings after age 60 are price indexed. The approximation of AIME by the average historical earnings follows previous Social Security literature, for example, Huggett and Ventura (1999) and De Nardi and others (1999).
} 
population of age 20 households is normalized to be unity in the baseline economy on the balanced growth path, that is,

$$
\int_{E} \mathrm{~d} X_{t}\left(20, e_{20}, 0,0\right)=1
$$

Let $\mathbf{1}_{[a=y]}$ be an indicator function that returns 1 if $a=y$ and 0 if $a \neq y$. Then, the law of motion of the measure of households is, for $i \in I=\{20, \ldots, 109\}$,

$$
\begin{aligned}
x_{t+1} & \left(\mathbf{s}_{i+1}\right)=\frac{\phi_{i}}{1+\nu} \int_{E \times A \times B} \mathbf{1}_{\left[a_{i+1}=a_{i+1}\left(\mathbf{s}_{i}, \mathbf{S}_{t} ; \mathbf{\Psi}_{t}\right)+q_{t}\right]} \\
& \times \mathbf{1}_{\left[b_{i+1}=b_{i+1}\left(w_{t} e_{i} h_{i}\left(\mathbf{s}_{i}, \mathbf{S}_{t} ; \mathbf{\Psi}\right), b_{i}\right)\right]} \pi_{i, i+1}\left(e_{i+1} \mid e_{i}\right) \mathrm{d} X_{t}\left(\mathbf{s}_{i}\right) .
\end{aligned}
$$

For simplicity, accidental bequests due to uncertain life span are captured by the government and distributed equally to all surviving working-age households in a lump-sum manner. The accidental bequests per household at the end of year $t$ is

$$
q_{t}=\frac{\sum_{i=20}^{109}\left(1-\phi_{i}\right) \int_{E \times A \times B} a_{i+1}\left(\mathbf{s}_{i}, \mathbf{S}_{t} ; \mathbf{\Psi}_{t}\right) \mathrm{d} X_{t}\left(\mathbf{s}_{i}\right)}{\sum_{i=20}^{64} \phi_{i} \int_{E \times A \times B} \mathrm{~d} X_{t}\left(\mathbf{s}_{i}\right)} .
$$

The steady-state condition is

$$
\mathbf{S}_{t+1}=\mathbf{S}_{t}
$$

for all $t$ and $\mathbf{s}_{i} \in I \times E \times A \times B$.

\subsection{The Firm's Problem}

National wealth $W_{t}$ is the sum of total private wealth and government net wealth $W_{g, t}$. Total labor supply $L_{t}$ is measured in efficiency units.

$$
\begin{aligned}
W_{t} & =\sum_{i=20}^{109} \int_{E \times A \times B} a_{i} \mathrm{~d} X_{t}\left(\mathbf{s}_{i}\right)+W_{g, t}, \\
L_{t} & =\sum_{i=20}^{109} \int_{E \times A \times B} e_{i} h_{i}\left(\mathbf{s}_{i}, \mathbf{S}_{t} ; \Psi_{t}\right) \mathrm{d} X_{t}\left(\mathbf{s}_{i}\right) .
\end{aligned}
$$

There is a perfectly competitive firm in this economy. In a closed economy, the capital stock is equal to national wealth, that is,

$$
K_{t}=W_{t},
$$


and gross national product $Y_{t}$ is determined by constant-returns-to-scale production,

$$
Y_{t}=F\left(K_{t}, L_{t}\right)
$$

The profit-maximizing condition of the firm is

$$
\begin{aligned}
& r_{t}+\delta=F_{K}\left(K_{t}, L_{t}\right), \\
& w_{t}\left(1+\tau_{P, t}^{\prime}\right)=F_{L}\left(K_{t}, L_{t}\right),
\end{aligned}
$$

where $\delta$ is the depreciation rate of capital and $\tau_{P, t}^{\prime}$ is the marginal payroll tax rate. ${ }^{29}$

\subsection{The Government's Policy Rules}

Government tax revenue consists of federal income tax $T_{I, t}$, payroll tax for Social Security $T_{P, t}$, and consumption tax $T_{C, t}$. These revenues equal:

$$
\begin{aligned}
& T_{I, t}=\sum_{i=20}^{109} \int_{E \times A \times B} \tau_{I, t}\left(w_{t} e_{i} h_{i}\left(\mathbf{s}_{i}, \mathbf{S}_{t} ; \mathbf{\Psi}_{t}\right), r_{t} a_{i}, \operatorname{tr}_{S S, t}\left(i, b_{i}\right)\right) \mathrm{d} X_{t}\left(\mathbf{s}_{i}\right), \\
& T_{P, t}=2 \times \sum_{i=20}^{109} \int_{E \times A \times B} \tau_{p, t}\left(w_{t} e_{i} h_{i}\left(\mathbf{s}_{i}, \mathbf{S}_{t} ; \mathbf{\Psi}_{t}\right)\right) \mathrm{d} X_{t}\left(\mathbf{s}_{i}\right), \\
& T_{C, t}=\sum_{i=20}^{109} \int_{E \times A \times B} \tau_{C, t} c_{i}\left(\mathbf{s}_{i}, \mathbf{S}_{t} ; \mathbf{\Psi}_{t}\right) \mathrm{d} X_{t}\left(\mathbf{s}_{i}\right) .
\end{aligned}
$$

Total Social Security benefits $\operatorname{Tr}_{S S, t}$ equals

$$
T r_{S S, t}=\sum_{i=20}^{109} \int_{E \times A \times B} \operatorname{tr}_{S S, t}\left(i, b_{i}\right) \mathrm{d} X_{t}\left(\mathbf{s}_{i}\right) .
$$

The law of motion of the government wealth (normalized by productivity growth and population growth) is

$$
W_{g, t+1}=\frac{1}{(1+\mu)(1+\nu)}\left\{\left(1+r_{t}\right) W_{g, t}+\left(T_{I, t}+T_{P, t}+T_{C, t}\right)-\operatorname{Tr}_{S S, t}-C_{g, t}\right\},
$$

where $C_{g, t}$ is government consumption.

\footnotetext{
${ }^{29}$ U.S. payroll taxes are divided equally between firms and employees. While the incidence of the tax does not depend on this division, our model explicitly includes the division for calibration purposes. In doing so, we ignore the small fraction of the representative firm's workforce whose wages exceed the payroll tax ceiling. However, the ceiling is enforced on the worker's share, as shown earlier.
} 


\subsection{Recursive Competitive Equilibrium}

Definition Recursive Competitive Equilibrium (Steady State): Let $\mathbf{s}_{i}=\left(i, e_{i}, a_{i}, b_{i}\right)$ be the individual state of households and $\boldsymbol{\Psi}$ be the time-invariant government policy rules,

$$
\Psi=\left\{W_{g}, C_{g}, \tau_{I}(.), \tau_{P}(.), \tau_{C}, \operatorname{tr}_{S S}(.)\right\}
$$

Factor prices $(r, w)$; accidental bequests $q$; the policy variables $\left(W_{g}, C_{g}, \tau_{C}, t r_{L S}\right)$; the parameters $\varphi$ of policy functions $\left(\tau_{I}(),. \tau_{P}(),. \operatorname{tr}_{S S}().\right)$; the value function of households, $v\left(\mathbf{s}_{i} ; \boldsymbol{\Psi}\right) ;$ the decision rule of households,

$$
\mathbf{d}\left(\mathbf{s}_{i} ; \Psi\right)=\left\{c_{i}\left(\mathbf{s}_{i} ; \Psi\right), h_{i}\left(\mathbf{s}_{i} ; \Psi\right), a_{i+1}\left(\mathbf{s}_{i} ; \Psi\right)\right\}
$$

and the measure of households, $x\left(\mathbf{s}_{i}\right)$, are in a steady-state recursive competitive equilibrium if, in every period, each household solves the utility maximization problem (5) - (9) taking $\Psi$ as given; the firm solves the profit maximization problem, and the capital and labor markets clear, that is, (20) - (25) hold; the government policy rules satisfy (26) - (30); and, the measure of households is constant, that is, (19) holds.

Definition Recursive Competitive Equilibrium (Equilibrium Transition Path): $\quad$ Let $\mathbf{s}_{i}=$ $\left(i, e_{i}, a_{i}, b_{i}\right)$ be the individual state of households, $\mathbf{S}_{t}=\left(x_{t}\left(\mathbf{s}_{i}\right), W_{g, t}\right)$ be the aggregate state of the economy, and $\Psi_{t}$ be the government policy rules known at the beginning of year $t$,

$$
\mathbf{\Psi}_{t}=\left\{W_{g, s+1}, C_{g, s}, \tau_{I, s}(.), \tau_{P, s}(.), \tau_{C}, \operatorname{tr}_{S S, s}(.)\right\}_{s=t}^{\infty} .
$$

A series of factor prices, accidental bequests, the policy variables, and the parameters of policy functions,

$$
\boldsymbol{\Omega}=\left\{r_{s}, w_{s}, q_{s}, W_{g, s+1}, C_{g, s}, \tau_{C, s}, \varphi_{s}\right\}_{s=t}^{\infty}
$$

the value function of households, $\left\{v\left(\mathbf{s}_{i}, \mathbf{S}_{s} ; \mathbf{\Psi}_{s}\right)\right\}_{s=t}^{\infty} ;$ the decision rule of households,

$$
\left\{\mathbf{d}\left(\mathbf{s}_{i}, \mathbf{S}_{s} ; \mathbf{\Psi}_{s}\right)\right\}_{s=t}^{\infty}=\left\{c_{i}\left(\mathbf{s}_{i}, \mathbf{S}_{s} ; \mathbf{\Psi}_{s}\right), h_{i}\left(\mathbf{s}_{i}, \mathbf{S}_{s} ; \mathbf{\Psi}_{s}\right), a_{i+1}\left(\mathbf{s}_{i}, \mathbf{S}_{s} ; \mathbf{\Psi}_{s}\right)\right\}_{s=t}^{\infty}
$$

and a series of the measure of households, $\left\{x_{s}\left(\mathbf{s}_{i}\right)\right\}_{s=t}^{\infty}$, are in a recursive competitive equilibrium if, in every period $s=t, \ldots, \infty$, each household solves the utility maximization 
Table 3: Parameters

\begin{tabular}{lll}
\hline Time preference parameter & $\beta$ & 0.986 \\
Share parameter for consumption & $\alpha$ & 0.473 \\
Coefficient of relative risk aversion & $\gamma$ & 2.0 \\
Capital share of output & $\theta$ & 0.32 \\
Depreciation rate of capital stock & $\delta$ & 0.046 \\
Long-term real growth rate & $\mu$ & 0.018 \\
Population growth rate & $\nu$ & 0.010 \\
Total factor productivity & $A$ & 0.983 \\
\hline
\end{tabular}

problem (5) - (9) taking $\boldsymbol{\Psi}_{t}$ as given; the firm solves the profit maximization problem, and the capital and labor markets clear, that is, (20) - (25) hold; and, the government policy rules satisfy (26) - (30).

\section{Calibration}

Table 3 summarizes the parameter choices. For the baseline economy on a balanced growth path, the degree of time preference $\beta$ is chosen so that the capital-output ratio is 2.8 ; total factor productivity $A$ is chosen so that the wage rate equals unity; and, the consumption share parameter $\alpha$ is chosen so that the average annual working hours of married couples between the ages of 20 and 64 are consistent with U.S. data. As explained below, a Cobb-DouglasCRRA utility function and a Cobb-Douglas production function are also used. ${ }^{30}$

The following sections describe the choice of functional forms and parameter values.

\subsection{Households}

Utility Function. Like the recent paper by Conesa and Krueger (1999) that focuses on Social Security reform, our model has elastic labor supply. We use the following CobbDouglas utility function with constant relative risk aversion (CRRA), which is compatible with the existence of a steady state:

$$
u\left(c_{i}, h_{i}\right)=\frac{\left\{\left(\left(1+n_{i} / 2\right)^{-\zeta} c_{i}\right)^{\alpha}\left(h_{i}^{\max }-h_{i}\right)^{1-\alpha}\right\}^{1-\gamma}}{1-\gamma},
$$

\footnotetext{
${ }^{30}$ The calibration basically follows that of the four-period model in Nishiyama (2002) but extends it significantly to a 90 -period setting.
} 
Table 4: Number of People Under 18 Years of Age in a Married Household

\begin{tabular}{lccc}
\hline Age cohorts & $\begin{array}{c}\text { Number of people } \\
\text { under age 18 }\end{array}$ & Age cohorts & $\begin{array}{c}\text { Number of people } \\
\text { under age 18 }\end{array}$ \\
\hline $20-24$ & 0.895 & $45-49$ & 1.011 \\
$25-29$ & 1.149 & $50-54$ & 0.445 \\
$30-34$ & 1.617 & $55-59$ & 0.188 \\
$35-39$ & 1.905 & $60-64$ & 0.094 \\
$40-44$ & 1.649 & $65-$ plus & $0.000^{*}$ \\
\hline Source: Authors' calculations using the Panel Study of Income Dynamics (PSID) \\
1993 Family Data. \\
*The number 0.000 for ages 65-plus is an assumption and not from PSID data.
\end{tabular}

where $\gamma$ is the coefficient of relative risk aversion, $n_{i}$ is the number of dependent children, $\zeta$ is the consumption adjustment parameter, and $h_{i}^{\max }$ is the maximum working hours. ${ }^{31}$ The coefficient of relative risk aversion is assumed to be 2.0. The number of dependent children by age cohort is calculated using the Panel Study of Income Dynamics (PSID) 1993 Family Data (see Table 4). The consumption adjustment parameter is assumed to be 0.6 .

The annual working hours in the model are the sum of the working hours of a husband and a wife. The average working hours of married households between ages 20 and 64 are 3,368 hours in the 1998 Survey of Consumer Finances (SCF). The maximum working hours are set at 8,760 , which equals two persons times 12 hours times 365 days. In this calibration, the parameter $\alpha$ is chosen to be 0.473 so that the average working hours of households between age 20 and age 64 equal 3,368 hours in the steady-state baseline economy.

Working Ability. The working ability in this calibration corresponds to the hourly wage (labor income per hour) of each household in the 1998 SCF. The average hourly wage of a married couple (family members \#1 and \#2 in SCF) used for the calibration is calculated by

$$
\text { Hourly Wage }=\frac{\text { Regular and Additional Salaries }(\# 1+\# 2)+\text { Welfare or Assistance }}{\text { Working Hours }(\# 1+\# 2)} .
$$

To capture the earnings risk a household is exposed to more precisely, unemployment or worker's compensation, TANF, food stamps, and other forms of welfare or assistance are added to the salaries before calculating the hourly wage. Failing to include these transfers

\footnotetext{
${ }^{31}$ In this setting, the growth-adjusted $\beta$ becomes $\beta(1+\mu)^{\alpha(1-\gamma)}$, which is 0.977 in the calibration.
} 
Table 5: Working Abilities of a Household (in U.S. Dollars per Hour)

\begin{tabular}{rrrrrrrr}
\hline & Percentile & \multicolumn{7}{c}{ Age cohorts } \\
\cline { 3 - 8 } & & $20-24$ & $25-29$ & $30-34$ & $35-39$ & $40-44$ & $45-49$ \\
\hline$e^{1}$ & $0-20$ th & 3.83 & 5.42 & 5.42 & 6.93 & 6.12 & 6.59 \\
$e^{2}$ & $20-40$ th & 7.07 & 8.64 & 9.76 & 11.28 & 11.36 & 12.70 \\
$e^{3}$ & $40-60$ th & 8.68 & 10.91 & 13.46 & 15.01 & 15.59 & 17.22 \\
$e^{4}$ & $60-80$ th & 10.67 & 14.01 & 18.08 & 19.96 & 22.09 & 23.22 \\
$e^{5}$ & $80-90$ th & 14.05 & 17.52 & 27.17 & 25.27 & 30.89 & 31.58 \\
$e^{6}$ & $90-95$ th & 18.20 & 22.48 & 33.71 & 33.38 & 48.59 & 44.31 \\
$e^{7}$ & $95-99$ th & 28.43 & 32.64 & 54.11 & 52.16 & 76.13 & 86.50 \\
$e^{8}$ & $99-100$ th & 36.81 & 46.09 & 167.15 & 186.47 & 221.34 & 301.99 \\
\hline & Percentile & \multicolumn{5}{c}{ Age cohorts } \\
\cline { 3 - 8 } & & $50-54$ & $55-59$ & $60-64$ & $65-69$ & $70-74$ & $75-79$ \\
\hline$e^{1}$ & $0-20$ th & 5.48 & 3.52 & 0.00 & 0.00 & 0.00 & 0.00 \\
$e^{2}$ & $20-40$ th & 11.53 & 10.06 & 4.54 & 0.00 & 0.00 & 0.00 \\
$e^{3}$ & $40-60$ th & 16.16 & 14.26 & 11.18 & 2.82 & 0.00 & 0.00 \\
$e^{4}$ & $60-80$ th & 23.44 & 21.28 & 18.16 & 10.37 & 1.81 & 0.00 \\
$e^{5}$ & $80-90$ th & 32.14 & 30.93 & 28.56 & 19.48 & 12.57 & 0.00 \\
$e^{6}$ & $90-95$ th & 43.01 & 44.10 & 59.36 & 27.68 & 29.03 & 1.96 \\
$e^{7}$ & $95-99$ th & 78.61 & 85.29 & 96.22 & 59.34 & 64.91 & 14.25 \\
$e^{8}$ & $99-100$ th & 314.59 & 379.44 & 421.55 & 299.25 & 195.73 & 146.14 \\
\hline
\end{tabular}

Source: Authors' calculations from 1998 SCF data.

would tend to lead to an overestimate of the risk-sharing benefits of the current federal income tax system. Table 5 shows the eight discrete levels of working abilities of five-year age cohorts. ${ }^{32}$ Taking a five-year moving average of these numbers, we obtain the working ability of each age cohort. According to Bureau of Labor Statistics data, the average hourly earnings of production workers have increased by 16.7 percent during the years from 1997 to 2001 . In the calibration, the numbers in the table are multiplied by 1.167 to convert the hourly wages in 1997 into those in 2001.

Markov Transition Matrix. The Markov transition matrix, $\Gamma$, of working ability is calculated from the hourly wage of people ages 30-39 in 1991 in the PSID individual data. To make the working ability process more persistent, the matrix is calculated as the transition

\footnotetext{
${ }^{32}$ Here, the hourly wage of a household that works less than 520 hours ( 10 hours a week per couple) is assumed to be zero. In the real economy, some households have fairly high working ability but choose not to work (for example, because of schooling). One observation of the age 20-24 cohort, which has an hourly wage of \$193.01, is ignored.
} 
from the average of years 1989 and 1990 to the average of years 1990 and 1991.

$$
\Gamma=\left(\begin{array}{llllllll}
0.7674 & 0.2049 & 0.0183 & 0.0045 & 0.0049 & 0.0000 & 0.0000 & 0.0000 \\
0.1810 & 0.6033 & 0.1844 & 0.0129 & 0.0000 & 0.0086 & 0.0046 & 0.0052 \\
0.0388 & 0.1517 & 0.6768 & 0.1220 & 0.0011 & 0.0046 & 0.0050 & 0.0000 \\
0.0126 & 0.0361 & 0.1039 & 0.7210 & 0.0980 & 0.0139 & 0.0145 & 0.0000 \\
0.0000 & 0.0081 & 0.0332 & 0.2360 & 0.6306 & 0.0676 & 0.0145 & 0.0100 \\
0.0000 & 0.0000 & 0.0000 & 0.0582 & 0.3224 & 0.5303 & 0.0891 & 0.0000 \\
0.0007 & 0.0000 & 0.0000 & 0.0354 & 0.0000 & 0.2827 & 0.6433 & 0.0379 \\
0.0000 & 0.0000 & 0.0000 & 0.0000 & 0.0000 & 0.0000 & 0.3553 & 0.6447
\end{array}\right),
$$

where $\Gamma(j, k)=\pi\left(e_{i+1}=e_{i+1}^{k} \mid e_{i}=e_{i}^{j}\right)$.

Population Growth and Mortality. The population growth rate $\nu$ is assumed to be 1.0 percent per year. The survival rates $\phi_{i}$ at the end of age $i=\{20, \ldots, 109\}$ are the weighted average of males and females in 1998 from Social Security Administration data (2001). The survival rates at the end of age 109 are replaced by zero.

\subsection{The Firm}

Production Function. Production takes the Cobb-Douglas form,

$$
F\left(K_{t}, L_{t}\right)=A_{t} K_{t}^{\theta} L_{t}^{1-\theta}
$$

To compute GNP, we use the sum of working hours in efficiency units as total labor supply $L_{t}$. The capital share of output $\theta$ is chosen by

$$
\theta=1-\frac{\text { Compensation of Employees }+(1-\theta) \times \text { Proprietors' Income }}{\text { National Income }+ \text { Consumption of Fixed Capital }}
$$

The average of $\theta$ in 1996-1998 is 0.32 . The annual growth rate $\mu$ is assumed to be 1.8 percent. The annual population growth rate $\nu$ is assumed to be 1.0 percent. Total factor productivity $A$ is chosen to be 0.983 so that the wage per unit of efficient labor is normalized to be unity. 
Table 6: Survival Rates in the United States (Weighted Average of Males and Females)

\begin{tabular}{|c|c|c|c|c|c|c|c|c|c|}
\hline Age & $\begin{array}{c}\text { Survival } \\
\text { Rate }\end{array}$ & Age & $\begin{array}{c}\text { Survival } \\
\text { Rate }\end{array}$ & Age & $\begin{array}{c}\text { Survival } \\
\text { Rate }\end{array}$ & Age & $\begin{array}{c}\text { Survival } \\
\text { Rate }\end{array}$ & Age & $\begin{array}{c}\text { Survival } \\
\text { Rate }\end{array}$ \\
\hline 20 & 0.999113 & 40 & 0.997978 & 60 & 0.989365 & 80 & 0.938048 & 100 & 0.676941 \\
\hline 21 & 0.999066 & 41 & 0.997820 & 61 & 0.988361 & 81 & 0.931804 & 101 & 0.658846 \\
\hline 22 & 0.999037 & 42 & 0.997654 & 62 & 0.987195 & 82 & 0.924980 & 102 & 0.639629 \\
\hline 23 & 0.999028 & 43 & 0.997465 & 63 & 0.985840 & 83 & 0.917566 & 103 & 0.619216 \\
\hline 24 & 0.999032 & 44 & 0.997267 & 64 & 0.984324 & 84 & 0.909481 & 104 & 0.597532 \\
\hline 25 & 0.999043 & 45 & 0.997044 & 65 & 0.982631 & 85 & 0.900623 & 105 & 0.574495 \\
\hline 26 & 0.999049 & 46 & 0.996797 & 66 & 0.980851 & 86 & 0.890904 & 106 & 0.550021 \\
\hline 27 & 0.999041 & 47 & 0.996534 & 67 & 0.979101 & 87 & 0.880258 & 107 & 0.524022 \\
\hline 28 & 0.999014 & 48 & 0.996258 & 68 & 0.977433 & 88 & 0.868650 & 108 & 0.496402 \\
\hline 29 & 0.998970 & 49 & 0.995960 & 69 & 0.975763 & 89 & 0.856070 & 109 & 0.467066 \\
\hline 30 & 0.998919 & 50 & 0.995626 & 70 & 0.973892 & 90 & 0.842518 & & \\
\hline 31 & 0.998865 & 51 & 0.995247 & 71 & 0.971745 & 91 & 0.828007 & & \\
\hline 32 & 0.998804 & 52 & 0.994823 & 72 & 0.969406 & 92 & 0.812554 & & \\
\hline 33 & 0.998735 & 53 & 0.994352 & 73 & 0.966856 & 93 & 0.796181 & & \\
\hline 34 & 0.998660 & 54 & 0.993826 & 74 & 0.964033 & 94 & 0.778913 & & \\
\hline 35 & 0.998573 & 55 & 0.993231 & 75 & 0.960839 & 95 & 0.761457 & & \\
\hline 36 & 0.998475 & 56 & 0.992570 & 76 & 0.957219 & 96 & 0.744011 & & \\
\hline 37 & 0.998368 & 57 & 0.991857 & 77 & 0.953175 & 97 & 0.726790 & & \\
\hline 38 & 0.998250 & 58 & 0.991094 & 78 & 0.948673 & 98 & 0.710031 & & \\
\hline 39 & 0.998122 & 59 & 0.990263 & 79 & 0.943665 & 99 & 0.693980 & & \\
\hline
\end{tabular}

Source: Authors' calculations from the Social Security Bulletin: Annual Statistical Supplement (2001). In the calibration, the survival rate at the end of age 109 is set to zero.

Fixed Capital and Private Wealth. The fixed capital $K_{t}$ for the calibration is obtained by "fixed reproducible tangible wealth" minus "durable goods owned by consumers" in the Survey of Current Business (1997). In 1990-1996, fixed capital accounted for 89.7 percent of fixed reproducible tangible wealth, and the capital-GDP ratio is approximately 2.8 .

To connect the total private wealth with the fixed capital, it is assumed that all of the private capital is owned by households and that part of the government-owned fixed capital is effectively owned by households in the form of government bonds.

$$
\begin{aligned}
& \text { Private Wealth (Excluding Durables) = Fixed Capital } \\
& \text { - Government-Owned Fixed Capital } \\
& + \text { Government Bonds Owned by Private Sector. }
\end{aligned}
$$


In the model, fixed capital is the sum of private wealth (excluding durables) and net government wealth. Based on the data from 1990 to 1996, net government wealth in the baseline economy is assumed to be 6.5 percent of total private wealth.

The Depreciation Rate of Fixed Capital. The depreciation rate of fixed capital $\delta$ is chosen by

$$
\delta=\frac{\text { Total Gross Investment }}{\text { Fixed Capital }}-\mu-\nu
$$

In 1997-2000, gross private domestic investment accounted for, on average, 17.5 percent of GDP, and gross government investment (federal and state) accounted for 3.2 percent of GDP. When the capital-output ratio is 2.8 , the ratio of gross investment to fixed capital is 7.4 percent. Subtracting the productivity and population growth rates, the annual depreciation rate is assumed to be 4.6 percent.

\subsection{Taxes and Transfers}

Income Taxes. For the federal income tax, the model uses the following tax function in Gouveia and Strauss (1994),

$$
\text { Federal Income Tax }=\phi_{0}\left(y-\left(y^{-\phi_{1}}+\phi_{2}\right)^{-1 / \phi_{1}}\right) \times \phi_{a d j}
$$

where $y$ is the taxable income (in thousands of dollars) of a household, which includes the taxable portion of Social Security benefits. In 2001, the standard deduction for a married household was $\$ 7,600$, and the exemption was $\$ 2,900$ per person. When the parameters are $\phi_{0}=0.41, \phi_{1}=0.85, \phi_{2}=0.015$, and $\phi_{a d j}=1.0$, this function replicates the statutory income tax schedule. But because of itemized deductions, the effective tax rate of highincome households is much lower. ${ }^{33}$ Since in 2000 the ratio of total private income tax to nominal GDP was $0.102, \phi_{a d j}$ is assumed to be 0.604 so that income tax revenue is 10.2 percent of GDP in the steady-state equilibrium.

In addition to federal income tax, a 4.0 percent state tax is assumed for income (excluding Social Security benefits) above the same standard deduction and exemptions.

\footnotetext{
${ }^{33}$ See Gouveia and Strauss (1994) for effective federal tax rates.
} 
Social Security. The Social Security system in the United States shares not only longevity risk among its participants but, due to its progressive formula, lifetime wage uncertainty as well, which our model captures. The tax rate levied on both employers and employees for Old-Age, Survivors, and Disability Insurance (OASDI) is 6.2 percent, and the tax rate for Medicare (HI) is 1.45 percent. In 2001, employee compensation above $\$ 80,400$ was not taxable for OASDI. So, the firm's profit-maximization problem becomes

$$
w \times(1+\text { Marginal Payroll Tax Rate })=A F_{L}(K, L),
$$

where the marginal payroll tax rate is 0.0765 (equal to $0.062+0.0145$ ).

Social Security benefits are based on each worker's average indexed monthly earnings (AIME), $b_{i} / 12$, and the replacement rate schedule in the United States. The replacement rates are 90 percent for the first $\$ 561,32$ percent for amounts between $\$ 561$ and $\$ 3,381$, and 15 percent for amounts above $\$ 3,381$. Since we are not able to accommodate health shocks in addition to our other stochastic variables, Medicare benefits are constant and included in government consumption. Since, in the policy experiments, government consumption is held constant relative to population growth and technological change, an increase (decrease) in Medicare tax revenue after a reform requires less (more) consumption tax revenue.

The Social Security benefits received by retired workers consisted of 69 percent of total OASDI benefits in December 2000. ${ }^{34}$ The calibration simply assumes that each elderly household receives other Social Security benefits - those for spouses, children, and disabled workers - proportionally. Hence, benefits are multiplied by 1.543 so that total OASDI benefits are equal to OASDI tax revenue in the baseline economy.

\section{The Lump-Sum Redistribution Authority}

In our policy experiments reported below, we measure the pure efficiency gains from a policy change using a Lump-Sum Redistribution Authority, following Auerbach and Kotlikoff (1987). We extend their analysis to a stochastic OLG model with heterogeneous agents.

Suppose that a new policy is announced at the beginning of period 1. The LSRA first makes a lump-sum transfer (tax if negative) to each living household to bring its remaining

\footnotetext{
${ }^{34}$ The number is from Social Security Administration (2001), Table 5.A4.
} 
expected lifetime utility back to its level in the baseline economy. Since the welfare gain or loss to each household depends on its own state, these lump-sum transfers (taxes) ${ }^{35}$ are shown as $\operatorname{tr}_{R_{1}}\left(\mathbf{s}_{i}\right)$ where $\mathbf{s}_{i}=\left(i, e_{i}, a_{i}, b_{i}\right)$ such that

$$
v\left(i, e_{i}, a_{i}+\operatorname{tr}_{R_{1}}\left(\mathbf{s}_{i}\right), b_{i}, \mathbf{S}_{1} ; \mathbf{\Psi}_{1}\right)=v\left(\mathbf{s}_{i}, \mathbf{S}_{0} ; \mathbf{\Psi}_{0}\right) .
$$

Next, the LSRA makes a lump-sum transfer (tax) to each future household (that is, each newborn household in periods $2,3, \ldots$ ) to make it as well off in the baseline economy, conditional on its initial state at age 20. These transfers (taxes) are shown as $\operatorname{tr}_{R_{2}}\left(\mathbf{s}_{20}, t\right)$ such that, for $t=2,3, \ldots$,

$$
v\left(20, e_{20}, 0+t r_{R_{2}}\left(\mathbf{s}_{20}, t\right), 0, \mathbf{S}_{t} ; \mathbf{\Psi}_{t}\right)=v\left(\mathbf{s}_{20}, \mathbf{S}_{0} ; \boldsymbol{\Psi}_{0}\right) .
$$

Finally, the LSRA makes additional lump-sum transfers (taxes) to the newborn households in periods $2,3, \ldots$, so that the net present value across all the LSRA transfers at the beginning of period 1 is zero. We assume these additional transfers are uniform on a growth-adjusted basis. With steady-state growth at rate $\mu$, the additional transfers are shown as $t r_{R_{3}}$, where

$$
\sum_{\mathbf{s}_{i}} \operatorname{tr}_{R_{1}}\left(\mathbf{s}_{i}\right) x_{1}\left(\mathbf{s}_{i}\right)+\sum_{t=2}^{\infty} \frac{(1+\mu)^{t-1} \sum_{\mathbf{s}_{20}}\left\{\operatorname{tr}_{R_{2}}\left(\mathbf{s}_{20}, t\right)+t r_{R_{3}}\right\} x_{t}\left(\mathbf{s}_{20}\right)}{\prod_{k=1}^{t-1}\left(1+r_{k}\right)}=0 .
$$

When $t r_{R_{3}}>0$, all of the current households would be as well off as the baseline economy and all of the future households would be strictly better off; hence, the new policy is Pareto improving after lump-sum redistributions. When $t r_{R_{3}}<0$, the alternative policy is Pareto inferior after lump-sum redistributions.

The wealth held by the LSRA (normalized by the productivity growth and population growth), $\left\{W_{a}\right\}_{t=1}^{\infty}$, is derived as

$$
\begin{aligned}
& W_{a, 1}=0, \\
& W_{a, 2}=\frac{-\sum_{\mathbf{s}_{i}} t r_{R_{1}}\left(\mathbf{s}_{i}\right) x_{1}\left(\mathbf{s}_{i}\right)}{(1+\mu)(1+\nu)}, \\
& W_{a, t}=\frac{\left(1+r_{t-1}\right) W_{a, t-1}-\sum_{\mathbf{s}_{20}}\left\{t_{R_{2}}\left(\mathbf{s}_{20}, t\right)+t r_{R_{3}}\right\} x_{t}\left(\mathbf{s}_{20}\right)}{(1+\mu)(1+\nu)}
\end{aligned}
$$

\footnotetext{
${ }^{35}$ These lump-sum transfers are negative of the compensating variations in wealth for current households.
} 
Table 7: Working Abilities of a Representative Household (In U.S. Dollars per Hour)

\begin{tabular}{lrrrrrr}
\hline Age Cohorts & $20-24$ & $25-29$ & $30-34$ & $35-39$ & $40-44$ & $45-49$ \\
$e^{1}$ & 9.87 & 12.44 & 17.58 & 18.78 & 21.81 & 23.80 \\
\hline Age Cohorts & $50-54$ & $55-59$ & $60-64$ & $65-69$ & $70-74$ & $75-79$ \\
$e^{1}$ & 22.98 & 22.33 & 20.67 & 11.34 & 7.62 & 2.13 \\
\hline \multicolumn{5}{l}{ Source: Authors' calculations from 1998 SCF data. }
\end{tabular}

for $t=3,4, \ldots, \infty$. National wealth $W_{t}$ is the sum of total private wealth, government net wealth $W_{g, t}$, and the LSRA wealth $W_{a, t}$. So, equation (20) is replaced with

$$
W_{t}=\sum_{i=20}^{109} \int_{E \times A \times B} a_{i} \mathrm{~d} X_{t}\left(\mathbf{s}_{i}\right)+W_{g, t}+W_{a, t},
$$

and the government policy rule is defined as

$$
\mathbf{\Psi}_{t}=\left\{W_{g, s+1}, W_{a, s+1}, C_{g, s}, \tau_{I, s}(.), \tau_{P, s}(.), \tau_{C}, \operatorname{tr}_{S S, s}(.)\right\}_{s=t}^{\infty} .
$$

\section{A Deterministic OLG Variant of Our Model}

In order to investigate the importance of idiosyncratic wages in our policy simulations reported below, we also consider a deterministic version of our OLG model in which a new representative household is born at each date, similar to the original Auerbach and Kotlikoff (1987) model. We assume that the working ability schedule of the representative household is that shown in Table 7. Those numbers are the weighted average of the values shown in Table 5. The representative household does not receive any working ability shocks, but there is still lifetime uncertainty in order to better isolate the risk-sharing role of the prereform progressive tax system.

Similar to the stochastic OLG economy with heterogeneous agents, the model is calibrated to the U.S. economy so that the capital-output ratio is 2.8 and average working hours (per couple) of working age households (ages 20-64) are 3,368 hours. Also, the wage rate (per efficiency unit of labor) is normalized to unity. The obtained parameters are as follows: 
Table 8: Parameters of the Representative Agent Model

\begin{tabular}{ccc}
\hline$\beta$ & $\alpha$ & $A$ \\
1.019 & 0.431 & 0.983 \\
\hline
\end{tabular}

\section{Policy Experiments}

We now consider the effects of reducing the marginal income tax rates by 10 percent proportionately and raising the consumption tax rate in each year to replace the lost revenue. ${ }^{36} \mathrm{We}$ first analyze this policy change using the baseline model described above, and we consider four cases: with and without wage uncertainty (life-span uncertainty is operative in all the experiments), and, for both of these two cases, without and with the Lump-Sum Redistribution Authority. We then report how the results change under some alternative model and reform assumptions.

\subsection{In the Baseline Economy}

In the baseline economy, recall that the federal income tax function is

$$
0.41 \times\left(y-\left(y^{-0.85}+0.015\right)^{-1 / 0.85}\right) \times \phi_{a d j},
$$

and the adjustment factor $\phi_{a d j}$ is set to 0.604 . In our policy experiment, $\phi_{a d j}$ is lowered by 10 percent to 0.544 , thereby reducing marginal income tax rates proportionately by 10 percent.

From the government budget constraint (30), the consumption tax revenue needed to finance the tax cut is

$$
T_{C, t}=(1+\mu)(1+\nu) W_{g, t+1}-\left(1+r_{t}\right) W_{g, t}-\left(T_{I, t}+T_{P, t}\right)+T r_{S S, t}+C_{g, t} .
$$

When the aggregate private consumption is

$$
C=\sum_{i=20}^{109} \int_{E \times A \times B} c_{i}\left(\mathbf{s}_{i}, \mathbf{S}_{t} ; \Psi\right) \mathrm{d} X_{t}\left(\mathbf{s}_{i}\right),
$$

\footnotetext{
${ }^{36}$ Of course, the complexity of solving a 10 percent replacement of the current income tax system is no different than solving for a full replacement. A partial replacement, however, takes relatively less computer time to solve since the transition path and final steady state are closer to the initial steady state. The qualitative conclusions reported herein about whether tax reform increases or decreases efficiency under the different scenarios considered below are not affected by the size of the reform.
} 
and a balanced budget is assumed, that is, $W_{g, t+1}=W_{g, t}$, the consumption tax rate $\tau_{C, t}$ is

$$
\tau_{C, t}=\left\{\left((1+\mu)(1+\nu)-\left(1+r_{t}\right)\right) W_{g, t}-\left(T_{I, t}+T_{P, t}\right)+T r_{S S, t}+C_{g, t}\right\} / C .
$$

\subsubsection{With Wage Uncertainty}

Tables 9A - 9C show the macroeconomic and welfare results of the tax reform in the stochastic version of our model with heterogeneous households. (The remaining tables are included at the end of this paper.) We first consider the case without the LSRA and then with it.

Without the Lump-Sum Redistribution Authority. The top panel of Table 9A shows that GNP and national wealth increase throughout the entire rational-expectations transition path. In the long run, national wealth, which is equal to capital stock in a closed economy, increases by 2.9 percent from the baseline economy, labor supply increases by 0.6 percent, and GNP increases by 1.3 percent. The interest rate decreases by 0.18 percentage points and the wage rate increases by 0.7 percent. To keep the government wealth (debt) at the same level as that of the baseline, the consumption tax rate increases by 1.3 percentage points.

The top panel of Table 9B shows average welfare changes faced by agents in a particular birth cohort and the (stochastic) income class they are in at the time of the reform. ${ }^{37}$ Each number is the population-weighted average of welfare changes across all households - with different wealth levels and different average historical earnings - in that birth-productivity cohort. ${ }^{38}$ All households over the age 80 in year 1, though, are in the lowest productivity group, $e^{1}$. The numbers are shown in units of $\$ 1,000$ and are adjusted (deflated) for economic growth over time. ${ }^{39}$ So, for example, the table shows that the welfare increases by -3.0 - that is, an average loss of $\$ 3,000$ - for the household who is age 40 and in productivity class $e^{1}$ in year 1, the year of reform. In words, households in that cohort would be willing to pay a one-time fee of $\$ 3,000$, on average, in order to avoid this reform. ${ }^{40}$ For households that

\footnotetext{
${ }^{37}$ In other words, the household's prereform and postreform value functions are computed conditional on their state at the time of reform. The household's state variables obviously change in future years.

${ }^{38}$ Reporting welfare changes conditional on each state variable would be cumbersome. We, therefore, report the average welfare gain within each birth cohort and income class. In the LSRA calculations reported below, though, redistribution is conditioned on each state variable.

${ }^{39}$ In other words, a household that turns 20 in year $t \geq 1$ actually gains $s \times(1+\mu)^{t-1}$, where $s$ is the amount shown in the table and $\mu$ is the per capita growth rate in the baseline economy.

${ }^{40}$ Unlike in the Auerbach and Kotlikoff model, our reported values cannot be expressed as a share of remaining full lifetime income since that value is stochastic in our model.
} 
have not yet reached the age 20 in year 1, the welfare numbers correspond to the amount of thousand dollars (adjusted for average growth) that they gain at age 20.

Notice that most households alive at the time of the reform are worse off, except for those in the highest two productivity classes, $e^{7}$ and $e^{8}$. While the gain to classes $e^{7}$ and $e^{8}$ is only a small fraction of their expected remaining lifetime income, it is still interesting that it is positive. Due to the serial correlation in productivity generated by the Markov earnings process, the two most productive classes at the time of the reform gain from a reduction in progressivity, and that gain outweighs the value of the lump-sum levy on their assets produced by moving to a consumption tax. Those in lower productivity classes at the time of the reform are, however, often worse off, including those who are only age 20 in year 1. Evidentially, the intertemporal and labor distortions caused by the prereform income tax system are less important to less productive agents than the risk sharing value that the prereform progressive tax system provides.

Most future households (those younger than age 20 in year 1), however, are better off from this reform. For example, the household who starts in productivity class $e^{2}$ at age 20 in year 81 gains 1.0 (that is, $\$ 1,000$ ), a value that has been adjusted (deflated) for average growth between year 1 and year 81. Evidentially, the positive long-run general-equilibrium effects of reform combined with the reduction in distortions outweigh the importance of the reduction in risk sharing for them.

With the Lump-Sum Redistribution Authority. To evaluate the overall efficiency of this tax change, the bottom panels of Tables 9A and 9B shows the same set of results with the LSRA. As without the LSRA, Table 9A shows that GNP and national wealth increase throughout the entire transition path, although the long-run gains are smaller than without the LSRA because the LSRA now transfers resources to those who otherwise would lose from reform in the short run. Government wealth (including the LSRA debt) declines by 2.8 percent as a percentage of GNP in the long run. Table 9B shows that households age 20 and older at the time of the reform are no better or worse off by construction: the LSRA transfers the exact amount of resources to hold their welfare unchanged. But all future households 
lose $\$ 3,200$, a sizeable reduction in efficiency for this experiment. ${ }^{41}$ In other words, the gain by future households from this reform is not enough to compensate the loss of current households in general equilibrium.

\subsubsection{Without Wage Uncertainty}

In order to estimate the importance of earnings uncertainty, Tables $10 \mathrm{~A}$ and $10 \mathrm{~B}$ show the results of the same tax reform within the deterministic version of our OLG economy. As before, we first consider the case without the LSRA and then the case with it.

Without the Lump-Sum Redistribution Authority. The top panel of Table 10A shows that tax reform increases national wealth and GNP throughout the entire transition path. In the long run, national wealth increases by 3.7 percent relative to the baseline economy. This increase is larger than that in a stochastic and heterogeneous economy. While precautionary saving increases in the stochastic version of our model as the risk sharing in the progressive income tax system is reduced, overall saving is more responsive to changes in after-tax interest rates in our deterministic model with representative households. Labor supply is also more responsive in the deterministic model, increasing by 1.5 percent in the long run, causing GNP to increase by 2.2 percent. The consumption tax rate increases by 0.8 percentage points in the long run.

The top panel of Table 10B shows that, without the LSRA, older households lose several thousand dollars from the reform, in large part from the wealth levy of their accumulated assets. Younger households, including those age 50 and below at the time of the reform, however, gain from the reduction in distortions caused by the reform, by as much as $\$ 23,000$ per household. Households born in the long run gain over $\$ 22,000$, benefiting from both the reduction in distortions and larger wages, although they face smaller returns to their saving.

With the Lump-Sum Redistribution Authority. The bottom panels of Tables 10A and 10B shows the results with the operative LSRA. Table 10A shows that, in contrast to the stochastic version of our model, the presence of the LSRA now leads to a larger long-run

\footnotetext{
${ }^{41}$ Remember that these numbers correspond to replacing only 10 percent of the progressive income tax system; full replacement would produce even larger losses.
} 
increase in national wealth and output. The reason is that younger households at the time of the reform gain more than the older households lose. Holding the remaining lifetime utility of agents alive at the time of the reform at their baseline level, therefore, nets the LSRA a positive level of resources in the short run.

Table 10B shows that, again, by construction of the LSRA, households alive at the time

of the reform gain $\$ 0$. But future households are better off by $\$ 25,100$ per household, a remarkable difference relative to the stochastic case considered earlier where each future household lost $\$ 3,200$.

\subsection{Alternative Assumptions}

We now report how the results change under three alternative model and reform assumptions using the stochastic version of our model: (i) a small open-economy; (ii) when the new consumption tax is progressive; and, (iii) when households are even more risk averse. None of these modifications, however, lead to positive efficiency gains following tax reform.

\subsubsection{Small Open Economy}

Tables 11A and 11B show the results of the tax change in a small open economy in which the interest rate and the wage rate are held fixed at the same levels as those in the baseline economy. Table 11A shows that both without and with the LSRA, the long-run increase in national wealth is larger, and the long-run increase in labor supply is smaller, than in a closed economy (compare with Table 9A). The top panel of Table 11B shows that without the LSRA, the average welfare loss of current households is smaller than it would be in a closed economy (compare with Table 9B). Since the interest rate does not fall in the small open economy after reform, some of the welfare losses by older households are mitigated. The bottom panel of Table 11B shows that with the LSRA, the welfare loss of current households is, again, $\$ 0$ by construction, but future households lose $\$ 1,000$. This loss is smaller in magnitude than the $\$ 3,200$ loss to each household in a closed economy since, in the open economy, capital deepening no longer generates a decrease in interest rates. 


\subsubsection{Postreform Consumption Tax is Progressive}

Tables $12 \mathrm{~A}$ and $12 \mathrm{~B}$ show the results of the tax change if a progressive consumption tax is introduced instead of the proportional consumption tax considered earlier. In this case, a flat consumption tax is levied on each household's annual consumption above $\$ 20,000$. Both without and with the LSRA, Table 12A shows that national wealth and GNP again increase throughout the entire transition path, although by slightly smaller amounts than with a proportional consumption tax, as shown in Table 9A. To keep the government's wealth at the same level as in the baseline, the consumption tax rate will have to increase by 1.9 percent in the long run, compared with 1.3 percent in Table 9A.

Without the LSRA, Table 12B shows that, for households age 50 or over at the time of the reform (year 1), only households in classes $e^{1}$ through $e^{3}$ are better off relative to the proportional consumption tax. The main reason is due to the larger revenue-neutral consumption tax rate in the progressive system, which levies a larger lump-sum tax on those assets that have already been accumulated at the time of the reform. The benefit of this lump-sum tax accrues mainly to future generations. Households born into income classes $e^{1}$ through $e^{6}$ in the long run are generally better off.

With the LSRA, each future household loses $\$ 2,800$ in welfare, which is smaller in magnitude than the $\$ 3,200$ loss in the proportional tax case. A key reason for the smaller loss is that the $\$ 20,000$ deduction generates a limited amount of risk sharing. However, this deduction is not as powerful of a risk-sharing device as the progressive marginal tax rate schedule found in the prereform system. For many households, income (and, hence, consumption) typically fluctuates above the $\$ 20,000$ deduction level for two reasons. First, unemployment leads to a drawing down of previous assets in order to support a level of consumption above the deduction. Second, unemployment insurance income (which is included in our income measure) provides some income as well. For those households, therefore, a modest decline in normal labor income produces only a small reduction in their average tax rates and no reduction in their marginal tax rates under a consumption tax with a deduction. 


\subsubsection{Households Are More Risk Averse}

Tables 13A and 13B show the results when the coefficient of relative risk aversion, $\gamma$, equals 4.0 instead of 2.0. Under our choice of constant relative risk aversion utility, a larger value of $\gamma$ generates more aversion to risk as well as more precautionary saving. Interestingly, without the LSRA, Table 13A shows that the long-run increase in national wealth after tax reform is actually slightly larger than that shown in the benchmark model (see Table 9A). On one hand, a smaller response might be expected since a household's saving is now less sensitive to changes in the after-tax interest rate for two reasons: (i) a greater share of capital in the prereform economy is now held for precautionary reasons and (ii) the intertemporal substitution elasticity (equal to $1 / \gamma$ ) is reduced. On the other hand, the risk-sharing provided by the prereform progressive income tax system is more valuable at a higher value of risk aversion: tax reform, therefore, generates relatively more precautionary saving in response to the reduction in risk sharing. Indeed, the LSRA experiment shown in Table 13B demonstrates that tax reform produces even larger efficiency losses than before, increasing from $\$ 3,200$ per future household to a loss of $\$ 5,500$ per future household.

\section{Concluding Remarks}

Tax reform has been analyzed in numerous papers. The calculation of the actual efficiency gains or losses stemming from tax reform, however, has been previously limited to models that assume an infinite-horizon representative agent, making it difficult to analyze the risk-sharing benefits of progressive taxation in the prereform system. This paper presents a new finite-horizon OLG model with idiosyncratic earnings and longevity risks. Following the deterministic OLG model developed by Auerbach and Kotlikoff (1987), we construct a Lump-Sum Redistribution Authority that is used to fix the remaining lifetime expected utilities of agents alive at the time of the tax reform at their prereform levels. The LSRA allows us to report actual efficiency gains associated with tax reform.

Our results point to the importance of incorporating the risk-sharing aspects of the prereform tax system into the analysis of tax reform. With stochastic wage shocks, replacing just 10 percent of the existing progressive income tax system with a revenue-neutral proportional 
consumption tax produced a $\$ 3,200$ loss to each future household under our benchmark parameter settings and model form. But when wage shocks were turned off and the model was recalibrated to match the same initial economy, future households gained $\$ 25,100$. The qualitative nature of these results were shown to be robust to a fairly wide range of parameter and model assumptions. A key reason for the efficiency loss with stochastic wages is the reduction in risk sharing relative to the prereform progressive income tax system.

\section{Appendix}

\section{A The Discretization of the State Space}

The state of a household is $\mathbf{s}_{i}=\left(i, e_{i}, a_{i}, b_{i}\right) \in I \times E \times A \times B$, where $I=\{20, \ldots, 109\}$, $E=\left[e^{\min }, e^{\max }\right], A=\left[a^{\min }, a^{\max }\right]$, and $B=\left[b^{\min }, b^{\max }\right]$. To compute an equilibrium, the state space of a household is discretized as $\widehat{\mathbf{s}}_{i} \in I \times \hat{E} \times \hat{A} \times \hat{B}$, where $\hat{E}=\left\{e^{1}, e^{2}, \ldots, e^{N_{e}}\right\}$, $\hat{A}=\left\{a^{1}, a^{2}, \ldots, a^{N_{a}}\right\}$, and $\hat{B}=\left\{b^{1}, b^{2}, \ldots, b^{N_{b}}\right\}$.

For all these discrete points, we compute the optimal decision of households, $\mathbf{d}\left(\widehat{\mathbf{s}}_{i}, \mathbf{S}_{t} ; \Psi_{t}\right)$ $=\left(c_{i}(),. h_{i}(),. a_{i+1}().\right) \in\left(0, c^{\max }\right] \times\left[0, h_{i}^{\max }\right] \times A$, and the marginal values, $\frac{\partial}{\partial a} v\left(\widehat{\mathbf{s}}_{i}, \mathbf{S}_{t} ; \mathbf{\Psi}_{t}\right)$, given the expected factor prices and policy variables.

To find the optimal end-of-period wealth, we use the Euler equation and bilinear interpolation (with respect to $a$ and $b$ ) of marginal value functions at the beginning of the next period. In this paper, $N_{e}, N_{a}$, and $N_{b}$ are 8,60 , and 10, respectively. Since there are 90 different ages, the total number of discrete states is 432,000 .

\section{B A Steady-State Equilibrium}

The algorithm to compute a steady-state equilibrium is as follows. Let $\boldsymbol{\Psi}$ denote the timeinvariant government policy rules $\mathbf{\Psi}=\left(W_{g}, C_{g}, \tau_{I}(),. \tau_{P}(),. \tau_{C}, \operatorname{tr}_{S S}().\right)$.

1. Set the initial values of factor prices $\left(r^{0}, w^{0}\right)$, accidental bequests $q^{0}$, the policy variables $\left(W_{g}^{0}, C_{g}^{0}, \tau_{C}^{0}\right)$, and the parameters $\varphi^{0}$ of policy functions $\left(\tau_{I}(),. \tau_{P}(),. \operatorname{tr}_{S S}().\right)$ if these are determined endogenously. ${ }^{42}$

\footnotetext{
${ }^{42}$ Actually, if we find the capital-labor ratio, both $r$ and $w$ are calculated from the given production function and depreciation rate.
} 
2. Given $\mathbf{\Omega}^{0}=\left(r^{0}, w^{0}, q^{0}, W_{g}^{0}, C_{g}^{0}, \tau_{C}^{0}, \varphi^{0}\right)$, find the decision rule of a household $\mathbf{d}\left(\widehat{\mathbf{s}}_{i}\right.$; $\left.\boldsymbol{\Psi}, \boldsymbol{\Omega}^{0}\right)$ for all $\widehat{\mathbf{s}}_{i} \in I \times \hat{E} \times \hat{A} \times \hat{B}^{43}$

(a) For age $i=109$, find the decision rule $\mathbf{d}\left(\widehat{\mathbf{s}}_{109} ; \Psi, \boldsymbol{\Omega}^{0}\right)$. Since the survival rate $\phi_{109}=0$, the end-of-period wealth $a_{i+1}\left(\widehat{\mathbf{s}}_{109} ;.\right)=0$ for all $\widehat{\mathbf{s}}_{109}$. Compute consumption and working hours $\left(c_{i}\left(\widehat{\mathbf{s}}_{109} ;.\right), h_{i}\left(\widehat{\mathbf{s}}_{109} ;.\right)\right)$ and, then, the marginal values $\frac{\partial}{\partial a} v\left(\widehat{\mathbf{s}}_{109} ; \boldsymbol{\Psi}, \boldsymbol{\Omega}^{0}\right)$ for all $\widehat{\mathbf{s}}_{109}$.

(b) For age $i=108, \ldots, 20$, find the decision rule $\mathbf{d}\left(\widehat{\mathbf{s}}_{i} ; \boldsymbol{\Psi}, \boldsymbol{\Omega}^{0}\right)$ and $\frac{\partial}{\partial a} v\left(\widehat{\mathbf{s}}_{i} ; \boldsymbol{\Psi}, \boldsymbol{\Omega}^{0}\right)$ for all $\widehat{\mathbf{s}}_{i}$, using $\frac{\partial}{\partial a} v\left(\widehat{\mathbf{s}}_{i+1} ; \boldsymbol{\Psi}, \boldsymbol{\Omega}^{0}\right)$ recursively.

i. Set the initial guess of $a_{i+1}^{0}\left(\widehat{\mathbf{s}}_{i} ;.\right)$.

ii. Given $a_{i+1}^{0}\left(\widehat{\mathbf{s}}_{i} ;.\right)$, compute $\left(c_{i}\left(\widehat{\mathbf{s}}_{i} ;.\right), h_{i}\left(\widehat{\mathbf{s}}_{i} ;.\right)\right)$. Plug these into the Euler equation with $\frac{\partial}{\partial a} v\left(\widehat{\mathbf{s}}_{i+1} ; \boldsymbol{\Psi}, \boldsymbol{\Omega}^{0}\right)$.

iii. If the Euler error is sufficiently small, then stop. Otherwise, update $a_{i+1}^{0}\left(\widehat{\mathbf{s}}_{i} ;.\right)$ and return to Step ii.

3. Find the steady-state measure of households $x\left(\widehat{\mathbf{s}}_{i} ; \mathbf{\Omega}^{0}\right)$ using the decision rule obtained in Step 2. This computation is done forward from age 20 to age 109. Repeat this step to iterate $q$ for $q^{1}$.

4. Compute new factor prices $\left(r^{1}, w^{1}\right)$, the policy variables $\left(W_{g}^{1}, C_{g}^{1}\right)$, and the parameters $\varphi^{1}$ of policy functions.

5. Compare $\Omega^{1}=\left(r^{1}, w^{1}, q^{1}, W_{g}^{1}, C_{g}^{1}, \tau_{C}^{1}, \varphi^{1}\right)$ with $\Omega^{0}$. If the difference is sufficiently small, then stop. Otherwise, update $\Omega^{0}$ and return to Step 2.

\section{An Equilibrium Transition Path}

Let's assume that the economy is in the initial steady state in period 0 , and that the new policy schedule $\Psi_{1}$, which was not expected in period 0 , is announced at the beginning of period 1 , where $\boldsymbol{\Psi}_{1}=\left\{W_{g, t+1}, C_{g, t}, \tau_{I, t}(.), \tau_{P, t}(.), \tau_{C, t}, \operatorname{tr}_{S S, t}(.)\right\}_{t=1}^{\infty}$. Let $\widehat{\mathbf{S}}_{1}=\left(x_{1}\left(\widehat{\mathbf{s}}_{i}\right), W_{g, 1}\right)$ be

\footnotetext{
${ }^{43}$ In the steady-state economy, the decision rule of a household $\mathbf{d}\left(\widehat{\mathbf{s}}_{i} ; \boldsymbol{\Psi}, \boldsymbol{\Omega}^{0}\right)$ is not a function of the aggregate state of economy $\widehat{\mathbf{S}}=\left(x\left(\widehat{\mathbf{s}}_{i}\right), W_{g}\right)$. The measure of household $x\left(\widehat{\mathbf{s}}_{i}\right)$ is determined uniquely by the steady-state condition, and the government's wealth $W_{g}$ is determined by the policy rule $\boldsymbol{\Psi}$.
} 
the aggregate state of the economy at the beginning of period 1 . The state of the economy $\widehat{\mathbf{S}}_{1}$ is usually equal to that of the initial steady state. The algorithm to compute a transition path to a new steady-state equilibrium (thereafter, final steady-state equilibrium) is as follows.

1. Choose a sufficiently large number, $T$, such that the economy is said to reach the new steady state within $T$ periods. ${ }^{44}$ Set the initial guess, $\left\{\boldsymbol{\Omega}_{t}^{0}\right\}_{t=1}^{T}$, on factor prices $\left(r_{t}^{0}, w_{t}^{0}\right)$, accidental bequests $q_{t}^{0}$, the policy variables $\left(W_{g, t+1}^{0}, C_{g, t}^{0}, \tau_{C, t}^{0}\right)$, and the parameters $\varphi_{t}^{0}$ of policy functions for $t=1,2, \ldots, T$.

2. Given $\boldsymbol{\Omega}_{T}^{0}=\left(r_{T}^{0}, w_{T}^{0}, q_{T}^{0}, W_{g, T}^{0}, C_{g, T}^{0}, \tau_{C, t}^{0}, \varphi_{T}^{0}\right)$, find the final steady-state decision rule $\mathbf{d}\left(\widehat{\mathbf{s}}_{i}, \widehat{\mathbf{S}}_{T} ; \mathbf{\Psi}_{T} ; \boldsymbol{\Omega}_{T}^{0}\right)$ and compute marginal values $\frac{\partial}{\partial a} v\left(\widehat{\mathbf{s}}_{i}, \widehat{\mathbf{S}}_{T} ; \mathbf{\Psi}_{T} ; \boldsymbol{\Omega}_{T}^{0}\right)$ for all $\widehat{\mathbf{s}}_{i} \in I \times \widehat{E} \times \widehat{A} \times \widehat{B}$. (See the algorithm for a steady-state equilibrium.)

3. For period $t=T-1, T-2, \ldots, 1$, based on the guess, $\Omega_{t}^{0}$, find backward the decision rule $\mathbf{d}\left(\widehat{\mathbf{s}}_{i}, \widehat{\mathbf{S}}_{t} ; \boldsymbol{\Psi}_{t} ; \boldsymbol{\Omega}_{t}^{0}\right)$ and marginal values $\frac{\partial}{\partial a} v\left(\widehat{\mathbf{s}}_{i}, \widehat{\mathbf{S}}_{t} ; \mathbf{\Psi}_{t} ; \boldsymbol{\Omega}_{t}^{0}\right)$ for all $\widehat{\mathbf{s}}_{i} \in I \times \widehat{E} \times$ $\widehat{A} \times \widehat{B}$, using the next-period marginal values $\frac{\partial}{\partial a} v\left(\widehat{\mathbf{s}}_{i}, \widehat{\mathbf{S}}_{t+1} ; \Psi_{t+1} ; \boldsymbol{\Omega}_{t+1}^{0}\right)$ recursively.

(a) For age $i=109$, find the decision rule $\mathbf{d}\left(\widehat{\mathbf{s}}_{109}, \widehat{\mathbf{S}}_{t} ; \boldsymbol{\Psi}_{t} ; \boldsymbol{\Omega}_{t}^{0}\right)$ and compute the marginal values $\frac{\partial}{\partial a} v\left(\widehat{\mathbf{s}}_{109}, \widehat{\mathbf{S}}_{t} ; \mathbf{\Psi}_{t} ; \boldsymbol{\Omega}_{t}^{0}\right)$ for all $\widehat{\mathbf{s}}_{109}$.

(b) For age $i=108, \ldots, 20$, find the decision rule $\mathbf{d}\left(\widehat{\mathbf{s}}_{i}, \widehat{\mathbf{S}}_{t} ; \boldsymbol{\Psi}_{t} ; \boldsymbol{\Omega}_{t}^{0}\right)$ and compute $\frac{\partial}{\partial a} v\left(\widehat{\mathbf{s}}_{i}, \widehat{\mathbf{S}}_{t} ; \mathbf{\Psi}_{t} ; \boldsymbol{\Omega}_{t}^{0}\right)$ for all $\widehat{\mathbf{s}}_{i}$, using $\frac{\partial}{\partial a} v\left(\widehat{\mathbf{s}}_{i+1}, \widehat{\mathbf{S}}_{t+1} ; \mathbf{\Psi}_{t+1} ; \boldsymbol{\Omega}_{t+1}^{0}\right)$ previously computed. ${ }^{45}$

i. Set the initial guess of $a_{i+1}^{0}\left(\widehat{\mathbf{s}}_{i} ;.\right)$.

ii. Given $a_{i+1}^{0}\left(\widehat{\mathbf{s}}_{i} ;.\right)$, compute $\left(c_{i}\left(\widehat{\mathbf{s}}_{i} ;.\right), h_{i}\left(\widehat{\mathbf{s}}_{i} ;.\right)\right)$. Plug these into the Euler equation with $\frac{\partial}{\partial a} v\left(\widehat{\mathbf{s}}_{i+1}, \widehat{\mathbf{S}}_{t+1} ; \mathbf{\Psi}_{t+1} ; \boldsymbol{\Omega}_{t+1}^{0}\right)$.

iii. If the Euler error is sufficiently small, then stop. Otherwise, update $a_{i+1}^{0}\left(\widehat{\mathbf{s}}_{i} ;.\right)$ and return to Step ii.

4. For period $t=1,2, \ldots, T-1$, compute forward $\boldsymbol{\Omega}_{t}^{1}=\left(r_{t}^{1}, w_{t}^{1}, q_{t}^{1}, W_{g, t+1}^{1}, C_{g, t}^{1}, \tau_{C, t}^{1}, \varphi_{t}^{1}\right)$ and the measure of households $x_{t+1}\left(\widehat{\mathbf{s}}_{i}\right)$, using the decision rule $\mathbf{d}\left(\widehat{\mathbf{s}}_{i}, \widehat{\mathbf{S}}_{t} ; \mathbf{\Psi}_{t} ; \boldsymbol{\Omega}_{t}^{0}\right)$ obtained in Step 3 and using the state of economy $\widehat{\mathbf{S}}_{t}=\left(x_{t}\left(\widehat{\mathbf{s}}_{i}\right), W_{g, t}\right)$ recursively.

\footnotetext{
${ }^{44}$ For this to be the case, the government's policy rule has to be time-invariant sufficiently before period $T$, that is, $\boldsymbol{\Psi}_{s}=\boldsymbol{\Psi}_{T}$ for $1 \leq s<T$.

${ }^{45}$ Note that this step does not use $\frac{\partial}{\partial a} v\left(\widehat{\mathbf{s}}_{i+1}, \widehat{\mathbf{S}}_{t} ; \boldsymbol{\Psi}_{t} ; \boldsymbol{\Omega}_{t}^{0}\right)$ recursively.
} 
5. Compare $\left\{\boldsymbol{\Omega}_{t}^{1}\right\}_{t=1}^{T}$ with $\left\{\boldsymbol{\Omega}_{t}^{0}\right\}_{t=1}^{T}$. If the difference is sufficiently small, then stop. Otherwise, update $\left\{\boldsymbol{\Omega}_{t}^{0}\right\}_{t=1}^{T}$ and return to Step 2. (If the final steady-state equilibrium is known, return to Step 3 instead.)

\section{The Lump-Sum Redistribution Authority}

When the Lump-Sum Redistribution Authority (LSRA) is assumed, the following computation is added to the iteration process for an equilibrium transition path.

1. [Step 1 in the previous subsection "An Equilibrium Transition Path" (hereafter ETP)] Add the wealth held by LSRA $\left\{W_{a, t}^{0}\right\}_{t=1}^{T}$ to $\left\{\boldsymbol{\Omega}_{t}^{0}\right\}_{t=1}^{T}$ and set the initial value.

2. [Steps 2 and 3 in ETP] For period $t=T, T-1, \ldots, 2$, compute the lump-sum transfers to newborn households (age 20) $\operatorname{tr}_{R_{2}}\left(\widehat{\mathbf{s}}_{20}, t\right)$ to make those households as much better off as the baseline economy.

(a) Set the initial value of lump-sum transfers $\operatorname{tr}_{R_{2}}\left(\widehat{\mathbf{s}}_{20}, \widehat{\mathbf{S}}_{t} ; \boldsymbol{\Psi}_{t} ; \boldsymbol{\Omega}_{t}\right)$ to newborn households.

(b) Given $\operatorname{tr}_{R_{2}}\left(\widehat{\mathbf{s}}_{20}, \widehat{\mathbf{S}}_{t} ; \Psi_{t} ; \boldsymbol{\Omega}_{t}\right)$, find the decision rule of newborn households $\mathbf{d}\left(\widehat{\mathbf{s}}_{20}\right.$, $\left.\widehat{\mathbf{S}}_{t} ; \boldsymbol{\Psi}_{t} ; \boldsymbol{\Omega}_{t}\right)$.

(c) Find the compensating variation in wealth $\Delta t r_{R_{2}}\left(\widehat{\mathbf{s}}_{20}, \widehat{\mathbf{S}}_{t} ; \Psi_{t} ; \boldsymbol{\Omega}_{t}\right)$ to make those households indifferent from the baseline economy. (Initial wealth of newborn households is assumed to be zero.) If the absolute value of $\Delta \operatorname{tr}_{R_{2}}\left(\widehat{\mathbf{s}}_{20}, \widehat{\mathbf{S}}_{t} ; \mathbf{\Psi}_{t} ; \boldsymbol{\Omega}_{t}\right)$ is sufficiently small, then go to Step (d). Otherwise, update $\operatorname{tr}_{R_{2}}\left(\widehat{\mathbf{s}}_{20}, \widehat{\mathbf{S}}_{t} ; \mathbf{\Psi}_{t} ; \boldsymbol{\Omega}_{t}\right)$ by adding $\Delta t r_{R_{2}}\left(\widehat{\mathbf{s}}_{20}, \widehat{\mathbf{S}}_{t} ; \Psi_{t} ; \boldsymbol{\Omega}_{t}\right)$ and return to Step (b).

(d) Given $t r_{R_{2}}\left(\widehat{\mathbf{s}}_{20}, \widehat{\mathbf{S}}_{t} ; \Psi_{t} ; \boldsymbol{\Omega}_{t}\right)$ and additional lump-sum transfers to newborns $t r_{R_{3}}$, find the decision rule of newborn households $\mathrm{d}\left(\widehat{\mathbf{s}}_{20}, \widehat{\mathbf{S}}_{t} ; \Psi_{t} ; \boldsymbol{\Omega}_{t}\right)$.

3. [Step 3 in ETP] For period $t=1$, compute the lump-sum transfers to current households (ages 20-109) $\operatorname{tr}_{R_{1}}\left(\widehat{\mathbf{s}}_{i}\right)$ to make those households as much better off as the baseline economy. 
(a) Set the initial value of lump-sum transfers $\operatorname{tr}_{R_{1}}\left(\widehat{\mathbf{s}}_{i}, \widehat{\mathbf{S}}_{1} ; \Psi_{1} ; \boldsymbol{\Omega}_{1}\right)$ to current households.

(b) Given $\operatorname{tr}_{R_{1}}\left(\widehat{\mathbf{s}}_{i}, \widehat{\mathbf{S}}_{1} ; \boldsymbol{\Psi}_{1} ; \boldsymbol{\Omega}_{1}\right)$, find the decision rule of current households $\mathbf{d}\left(\widehat{\mathbf{s}}_{i}, \widehat{\mathbf{S}}_{1}\right.$; $\left.\Psi_{1} ; \boldsymbol{\Omega}_{1}\right)$.

(c) Find the compensating variation in wealth to make those households indifferent from the baseline economy. Compute $\Delta t r_{R_{1}}\left(\widehat{\mathbf{s}}_{i}, \widehat{\mathbf{S}}_{1} ; \boldsymbol{\Psi}_{1} ; \boldsymbol{\Omega}_{1}\right)$ as the difference from current beginning-of-period wealth. If the absolute value of $\Delta \operatorname{tr}_{R_{1}}\left(\widehat{\mathbf{s}}_{i}, \widehat{\mathbf{S}}_{1}\right.$; $\left.\mathbf{\Psi}_{1} ; \boldsymbol{\Omega}_{1}\right)$ is sufficiently small, then stop. Otherwise, update $\operatorname{tr}_{R_{1}}\left(\widehat{\mathbf{s}}_{i}, \widehat{\mathbf{S}}_{1} ; \boldsymbol{\Psi}_{1} ; \boldsymbol{\Omega}_{1}\right)$ by adding $\Delta t r_{R_{1}}\left(\widehat{\mathbf{s}}_{i}, \widehat{\mathbf{S}}_{1} ; \Psi_{1} ; \boldsymbol{\Omega}_{1}\right)$ and return to Step (b).

4. [Before Step 4 in ETP] Compute an additional lump-sum transfer $\operatorname{tr}_{R_{3}}$ so that the net present value of all transfers becomes zero. Compute the wealth held by LSRA, $\left\{W_{a, t}^{1}\right\}_{t=1}^{T}$, which will be used to calculate national wealth.

5. [After Step 4 in ETP] Recompute $t r_{R_{3}}$ and $\left\{W_{a, t}^{1}\right\}_{t=1}^{T}$ using new interest rates $\left\{r_{t}\right\}_{t=1}^{T}$. Compare $\left\{W_{a, t}^{1}\right\}_{t=1}^{T}$ with $\left\{W_{a, t}^{0}\right\}_{t=1}^{T}$. If the difference is sufficiently small, then stop. Otherwise, update $\left\{W_{a, t}^{0}\right\}_{t=1}^{T}$ and return to Step 2 . 


\section{References}

[1] Aiyagari, S. Rao (1995). "Optimal Capital Income Taxation with Incomplete Markets, Borrowing Constraints, and Constant Discounting." Journal of Political Economy, 106: 1158-1175.

[2] Altig, David, Alan Auerbach, Laurence Kotlikoff, Kent Smetters, and Jan Walliser (2001). "Simulating Fundamental Tax Reform in the United States." American Economic Review, 91, 3: 574-595.

[3] Auerbach, Alan, Jagadeesh Gokhale, and Laurence Kotlikoff (1994). "Generational Accounting: A Meaningful Way to Evaluate Fiscal Policy.” Journal of Economic Perspectives, 8, 1: 73-94.

[4] Auerbach, Alan and Kevin Hassett (2001). “Tax Policy and Horizontal Equity.” In Kevin Hassett and R. Glenn Hubbard, Eds., Inequality and Tax Policy. The AEI Press: Washington, D.C.

[5] Auerbach, Alan and James Hines, Jr. (2001). "Taxation and Economic Efficiency." NBER Working Paper \#8181.

[6] Auerbach, Alan and Laurence Kotlikoff (1987). Dynamic Fiscal Policy. Cambridge University Press.

[7] Bradford, David (1986). Untangling the Income Tax. Cambridge, Mass.: Harvard University Press.

[8] Bureau of Economic Analysis (1997). "Fixed Reproducible Tangible Wealth in the United States: Revised Estimates for 1993-95 and Summary Estimates for 1925-96." Survey of Current Business, September, 37-38.

[9] Conesa, Juan and Dirk Krueger (1999). "Social Security Reform with Heterogeneous Agents." Review of Economic Dynamics, 2, 4: 757-795. 
[10] De Nardi, Mariacristina, Selahattin İmrohoroğlu, and Thomas J. Sargent (1999). "Projected U.S. Demographics and Social Security." Review of Economic Dynamics, 2: 575615.

[11] Engen, Eric and William Gale (1996). "The Effects of Fundamental Tax Reform on Savings." In Economic Effects of Fundamental Tax Reform, edited by Henry J. Aaron and William G. Gale. Washington, D.C.: The Brookings Institution Press.

[12] Engen, Eric, Jane Gravelle, and Kent Smetters (1997). "Dynamic Tax Models: Why They Do the Things they Do." National Tax Journal, 50, 3: 657-682.

[13] Fullerton, Don and Diane Lim Rogers (1993). Who Bears the Lifetime Tax Burden? Washington, D.C.: Brookings Institution Press.

[14] Gouveia, Miguel and Robert P. Strauss (1994). "Effective Federal Individual Income Tax Functions: An Exploratory Empirical Analysis.” National Tax Journal, 47, 317-339.

[15] Gravelle, Jane (2002). "Behavioral Responses to a Consumption Tax." In United States Tax Reform in the 21st Century, George Zodrow and Peter Mieszkowski, Editors. Cambridge University Press.

[16] Hall, Robert E. and Alvin Rabushka (1995). The Flat Tax, 2nd ed. Stanford, Calif.: Hoover Institution Press.

[17] Huggett, Mark and Gustavo Ventura (1999). "On the Distributional Effects of Social Security Reform." Review of Economic Dynamics, 2: 498-531.

[18] Jorgenson, Dale and Kun-Young Yun (2001). Lifting the Burden: Tax Reform, the Cost of Capital, and U.S. Economic Growth, MIT Press.

[19] Judd, Kenneth (1999). "Optimal Taxation and Spending in General Competitive Growth Models.” Journal of Public Economics, 71 (1): 1-26.

[20] Mirrlees, James (1971). "An Exploration in the Theory of Optimal Income Taxation." Review of Economic Studies, 38: 175-208. 
[21] Nishiyama, Shinichi (2002). "Bequests, Inter Vivos Transfers, and Wealth Distribution." Review of Economic Dynamics, 5: 892-931.

[22] Social Security Administration (2001). Social Security Bulletin: Annual Statistical Supplement.

[23] Stokey, Nancy and Sergio Rebelo (1995). “Growth Effects of Flat-Rate Taxes.” Journal of Political Economy, 103: 519-550.

[24] Summers, Lawrence (1981). "Capital Income Taxation and Accumulation in a Life Cycle Model." American Economic Review, 71: 533-544. 


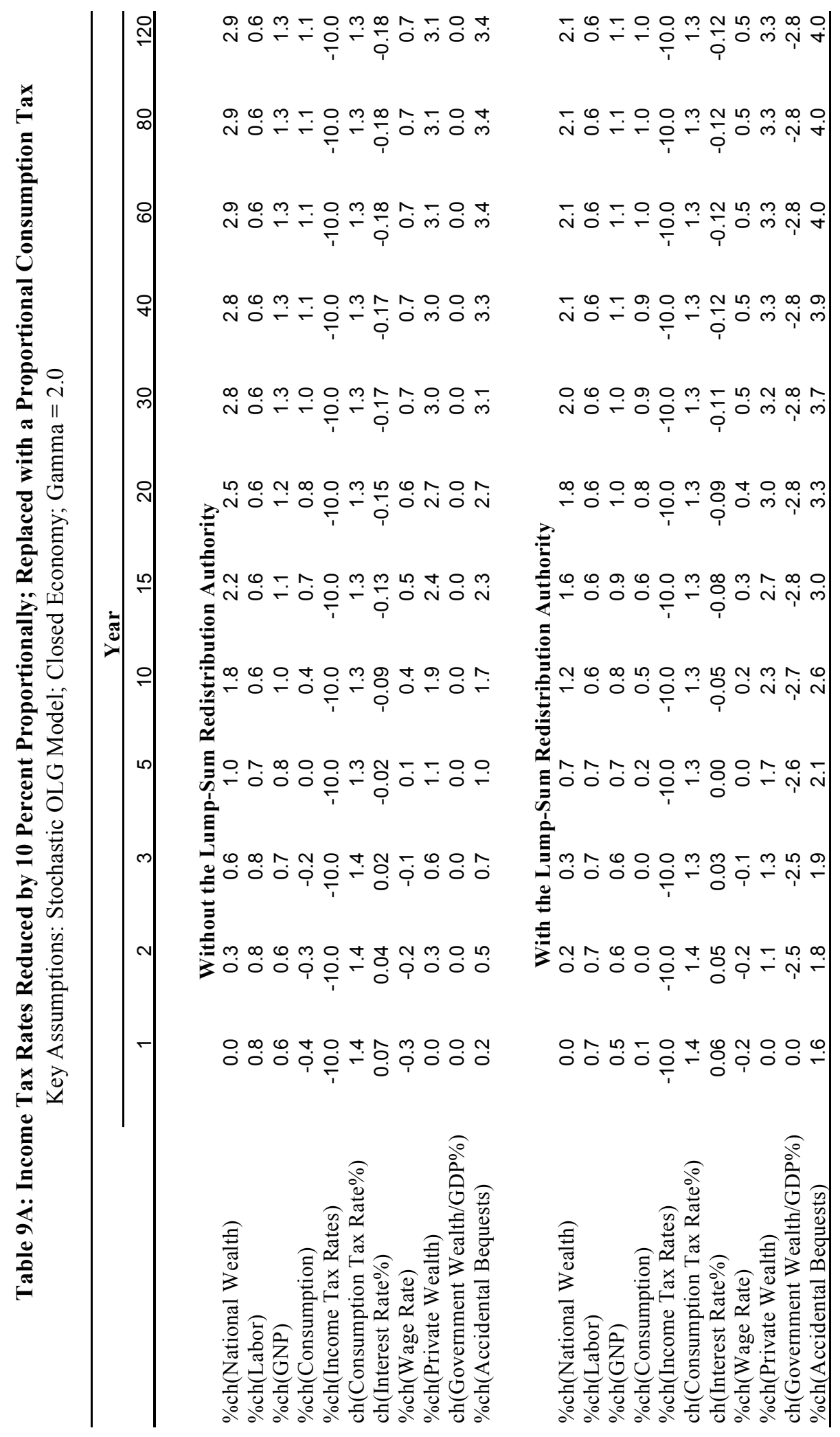




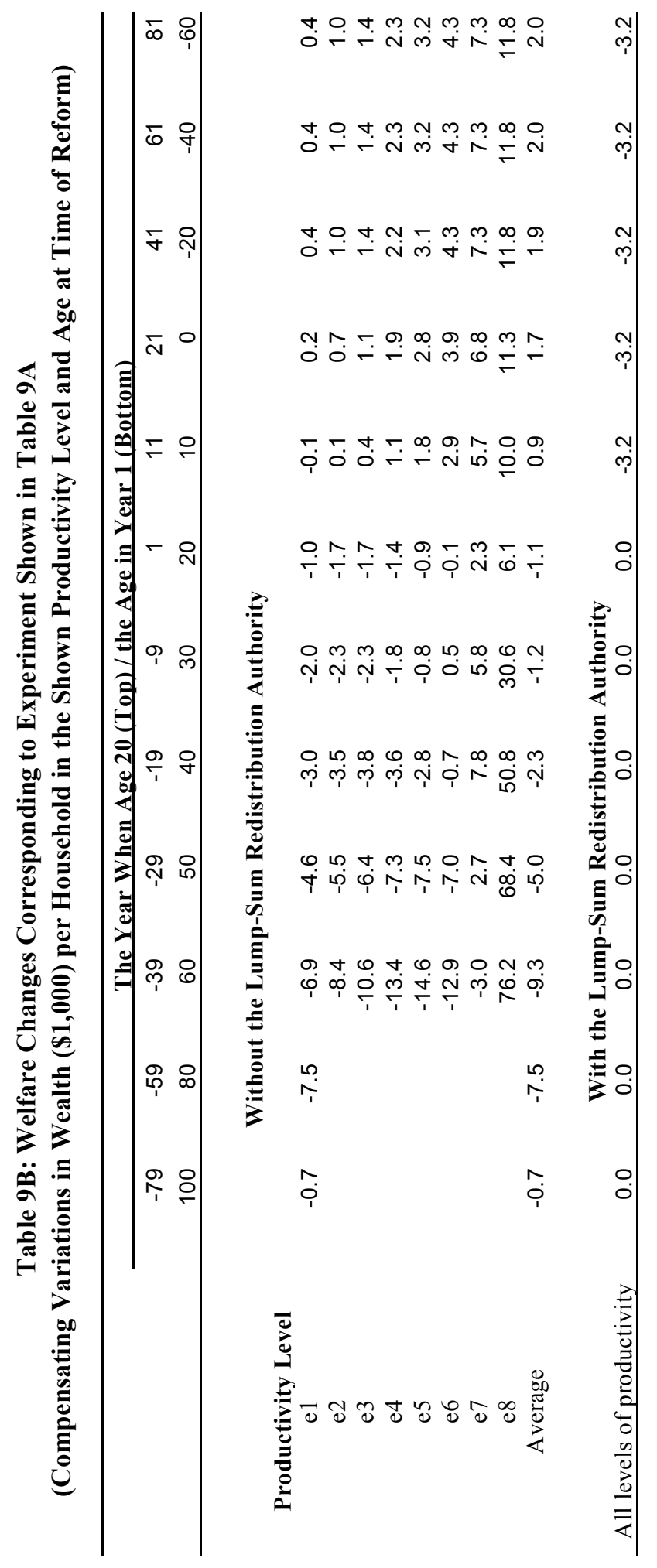




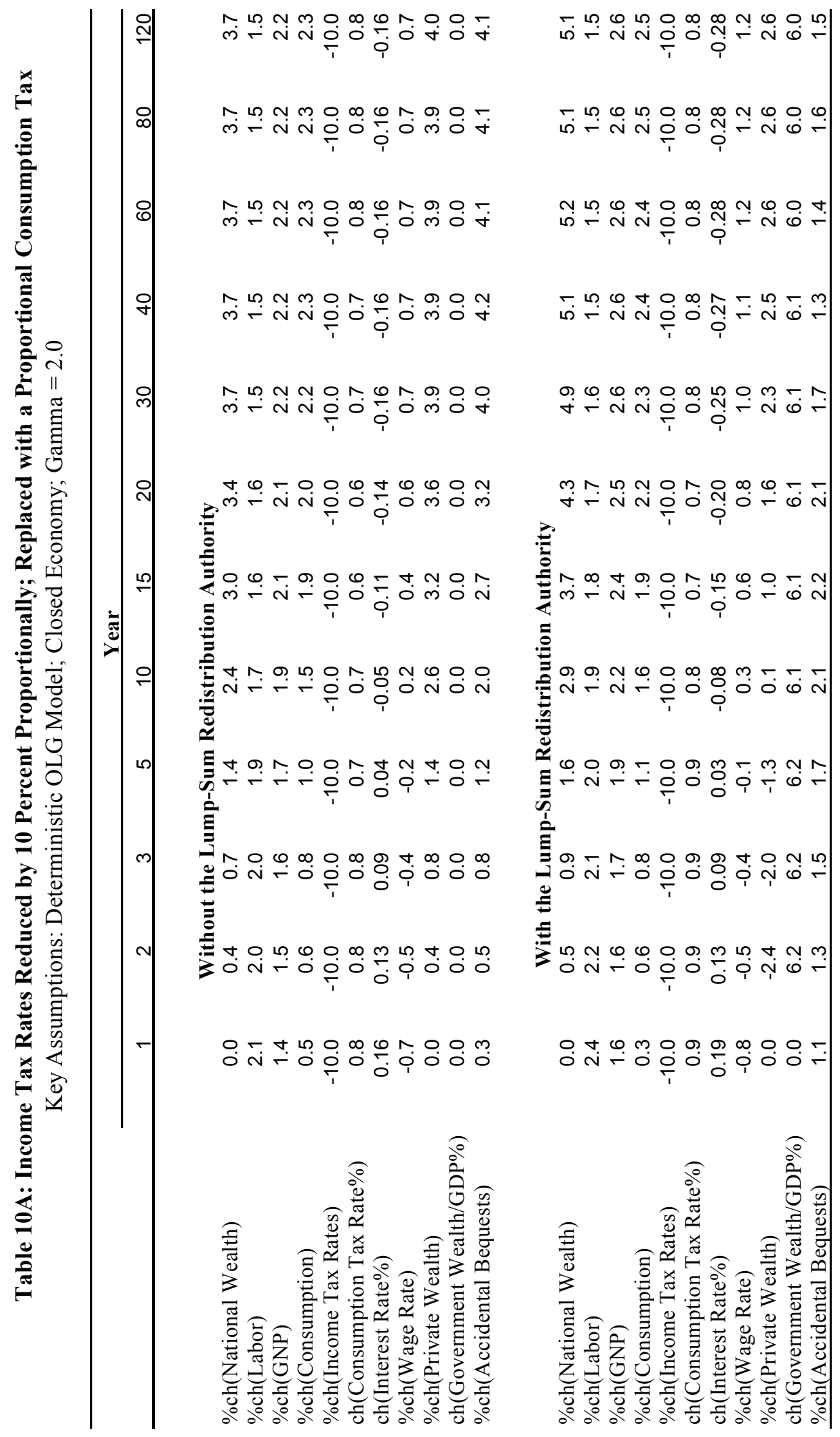




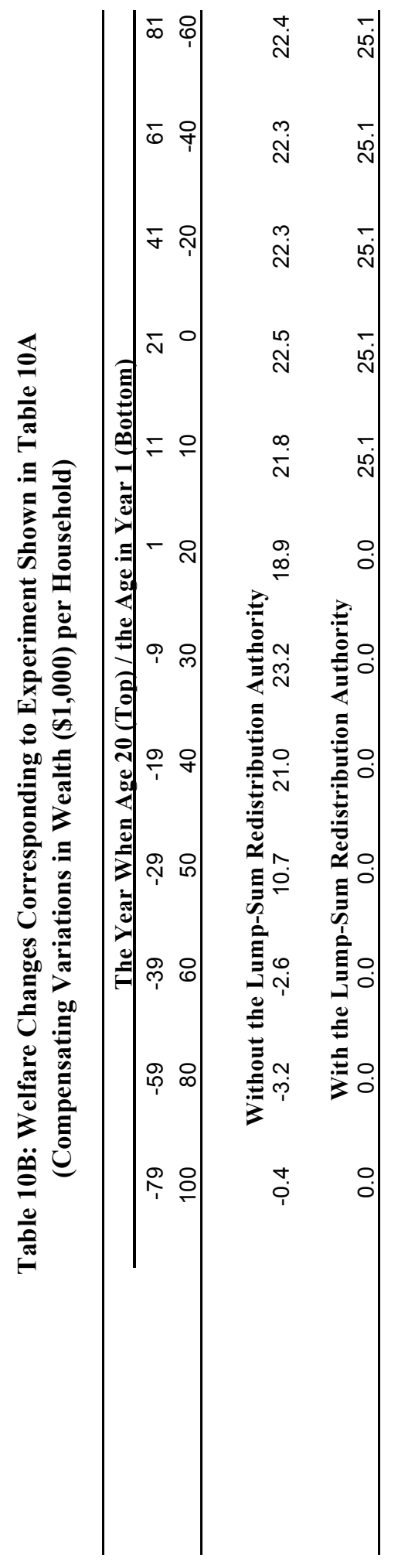




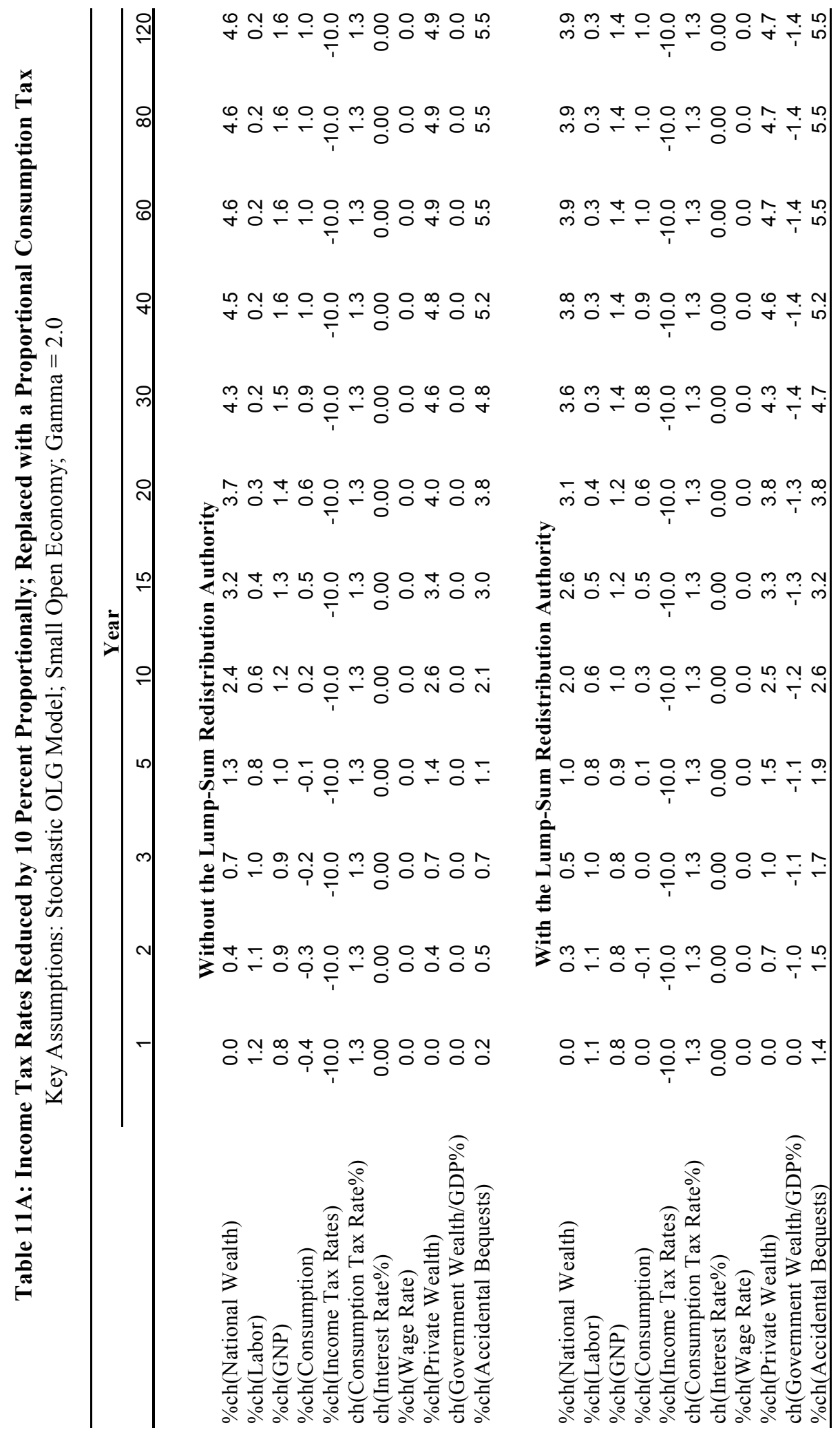




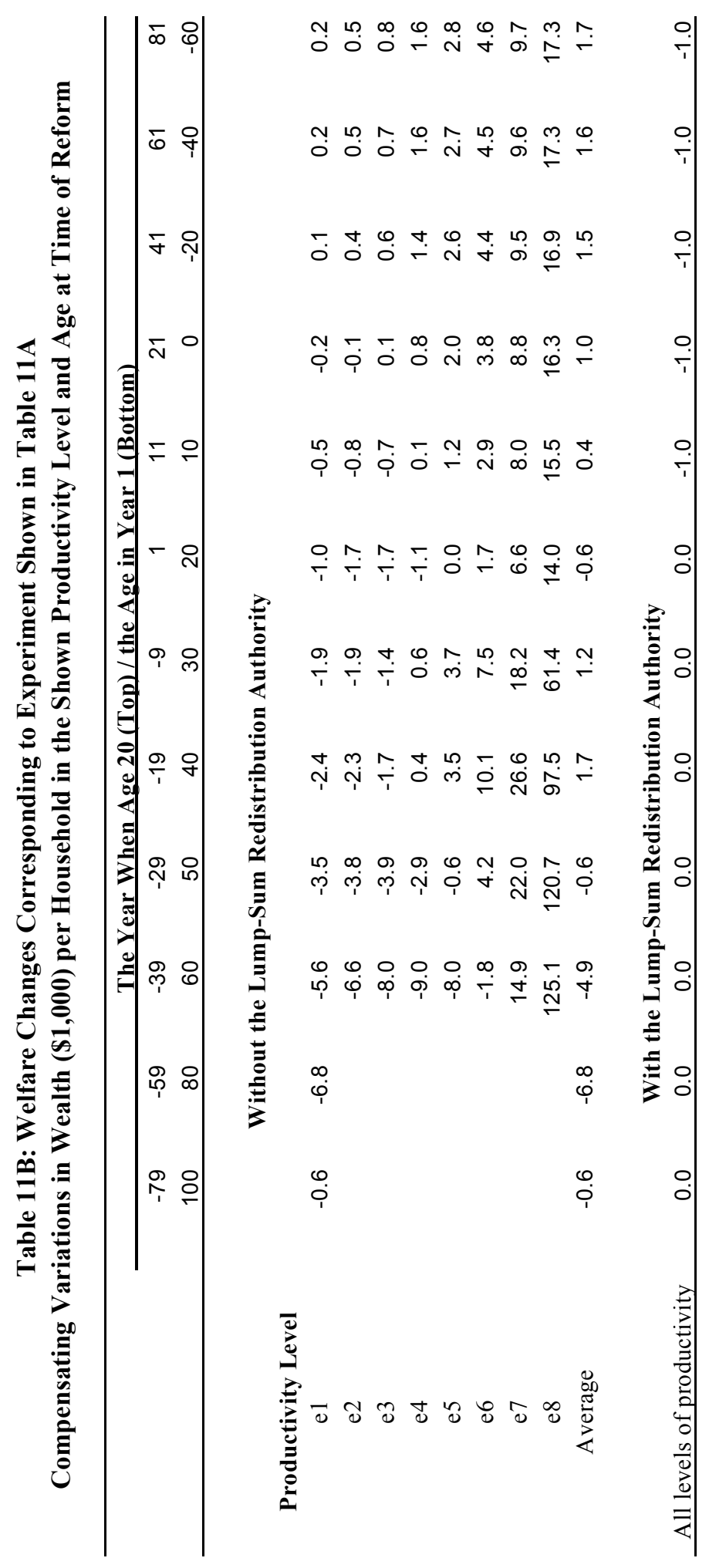




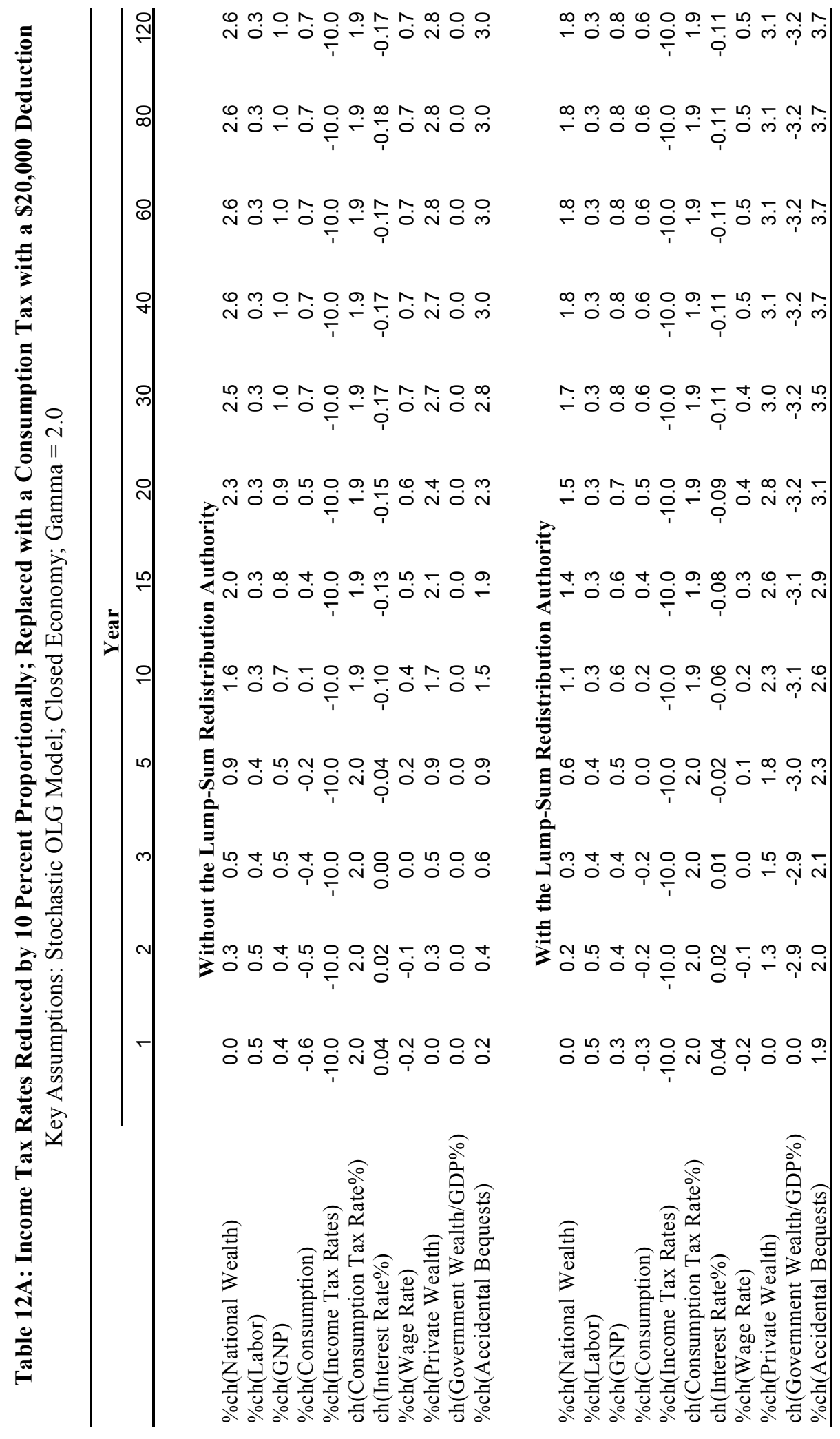




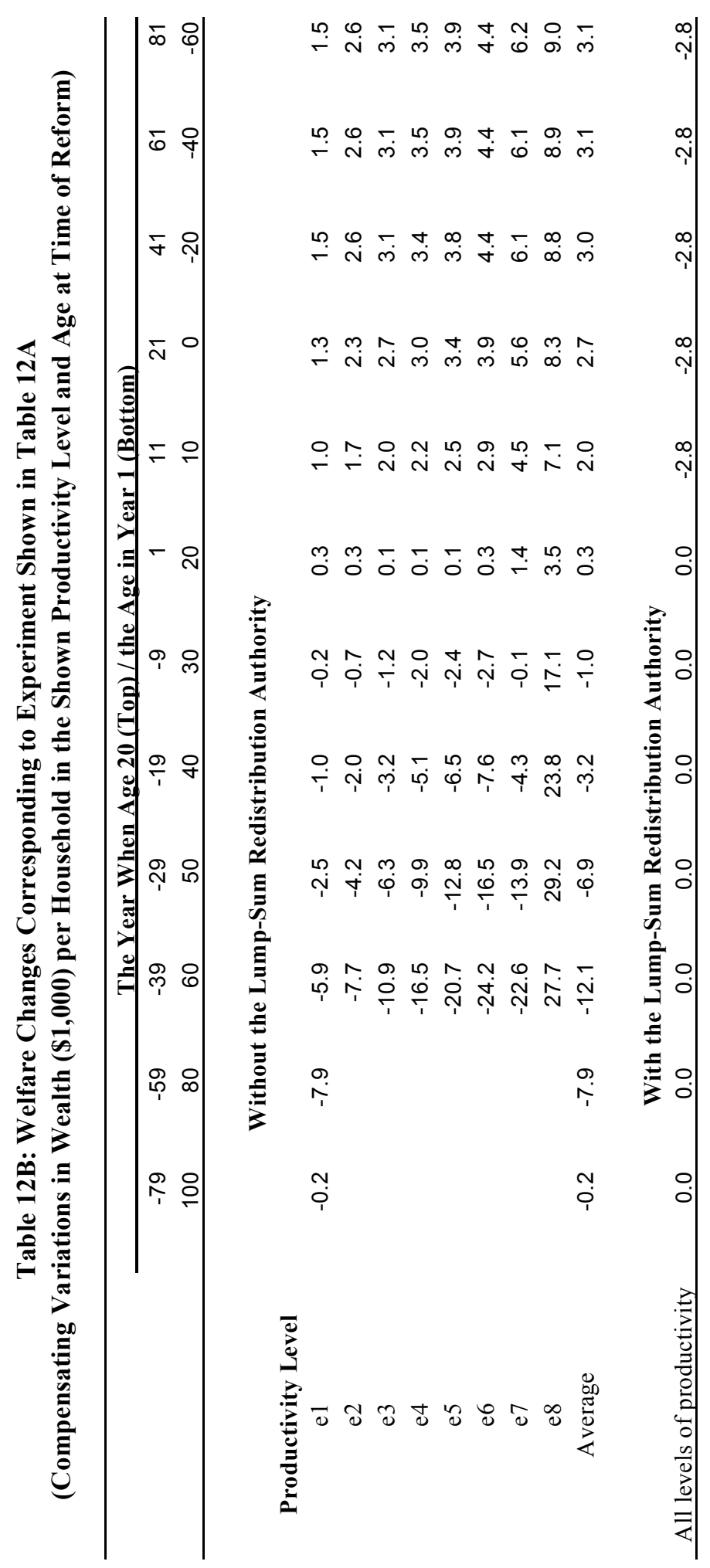




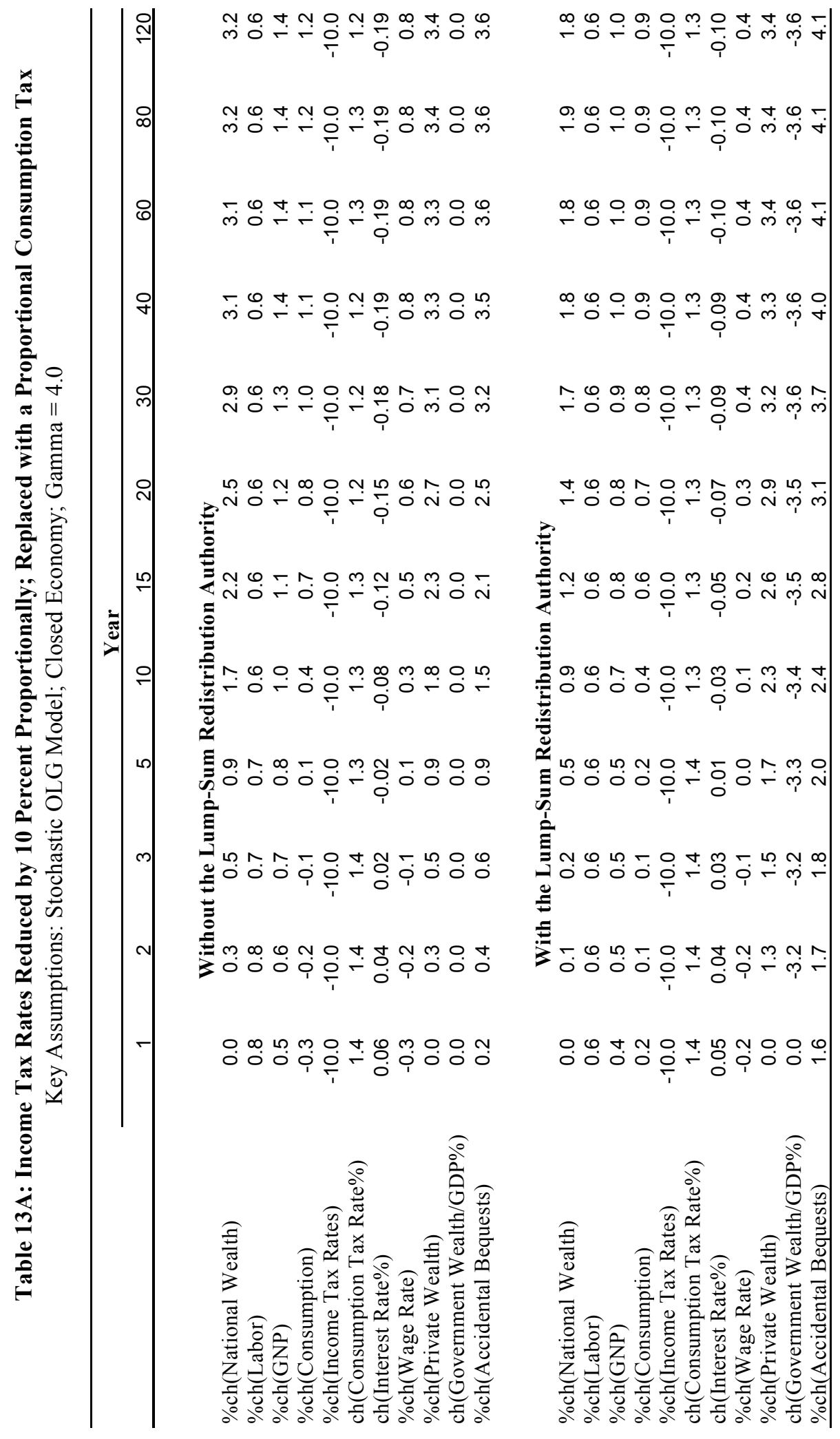




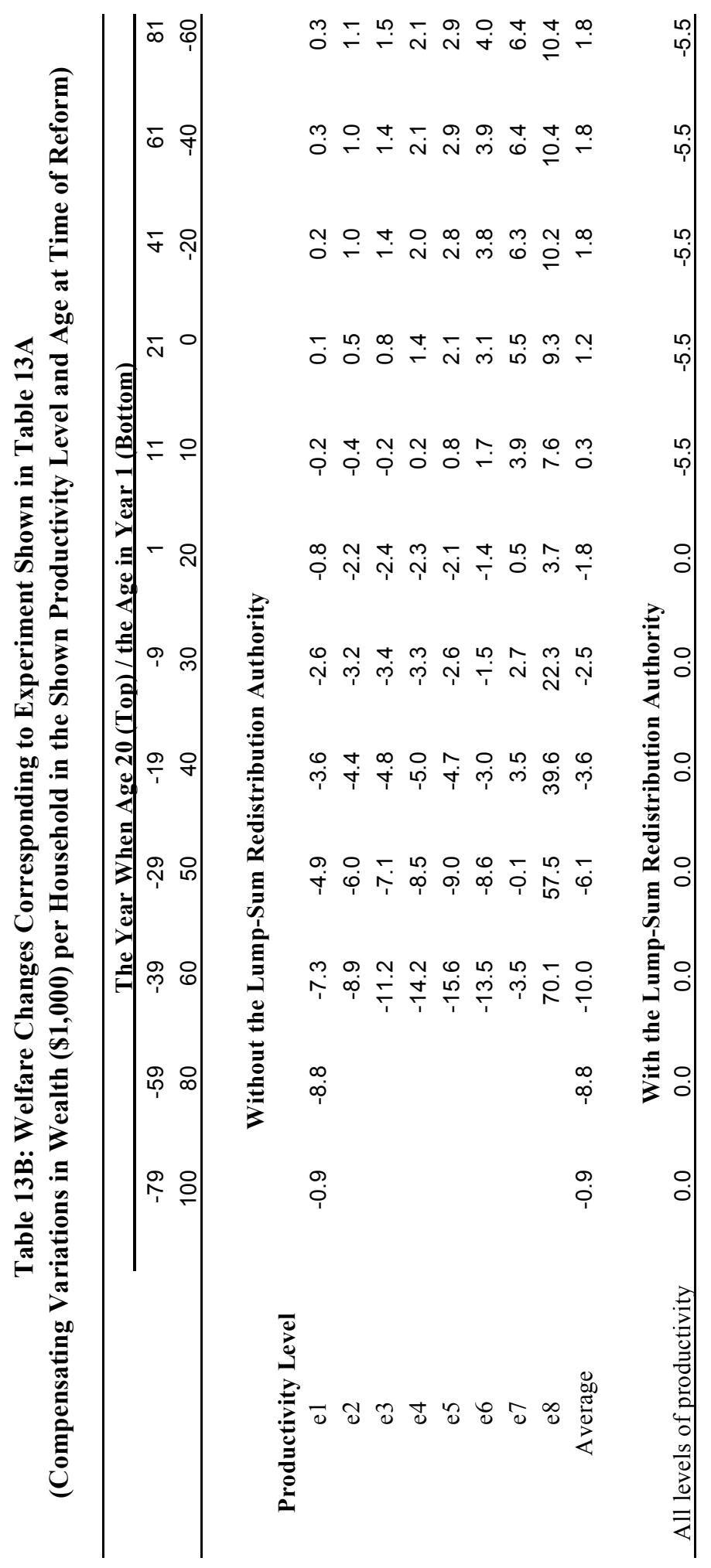

